\title{
Microstructural Characterization of the Heat-Affected Zones in Grade 92 Steel Welds: Double-Pass and Multipass Welds
}

\begin{abstract}
X. XU, G.D. WEST, J.A. SIEFERT, J.D. PARKER, and R.C. THOMSON $\mathbb{B}$
The microstructure in the heat-affected zone (HAZ) of multipass welds typical of those used in power plants and made from 9 wt pct chromium martensitic Grade 92 steel is complex. Therefore, there is a need for systematic microstructural investigations to define the different regions of the microstructure across the HAZ of Grade 92 steel welds manufactured using the traditional arc welding processes in order to understand possible failure mechanisms after long-term service. In this study, the microstructure in the HAZ of an as-fabricated two-pass bead-on-plate weld on a parent metal of Grade 92 steel has been systematically investigated and compared to a complex, multipass thick section weldment using an extensive range of electron and ion-microscopy-based techniques. A dilatometer has been used to apply controlled thermal cycles to simulate the microstructures in distinctly different regions in a multipass HAZ using sequential thermal cycles. A wide range of microstructural properties in the simulated materials were characterized and compared with the experimental observations from the weld HAZ. It has been found that the microstructure in the HAZ can be categorized by a combination of sequential thermal cycles experienced by the different zones within the complex weld metal, using the terminology developed for these regions based on a simpler, single-pass bead-on-plate weld, categorized as complete transformation, partial transformation, and overtempered.
\end{abstract}

https://doi.org/10.1007/s11661-017-4446-6

(C) The Author(s) 2018. This article is an open access publication

\section{INTRODUCTION}

GRADE 92 steel is currently in use in the power generation industry in product forms such as tubes, pipes, and forgings. It has been specified for use in new plants and also as a replacement material for lower alloy steel grades and another 9 wt pct $\mathrm{Cr}$ steel, Grade 91, because of its superior creep strength and the ability to use thinner section material for the same, or improved, mechanical properties. The material is normally supplied in a normalized and tempered condition used to achieve a tempered martensitic matrix stabilized by grain boundary $\mathrm{M}_{23} \mathrm{C}_{6}$ carbides and $\mathrm{MX}$ carbonitrides. ${ }^{[1]}$ Typical normalization heat treatments are performed in the range of $1313 \mathrm{~K}$ to $1353 \mathrm{~K}\left(1040{ }^{\circ} \mathrm{C}\right.$ to $1080{ }^{\circ} \mathrm{C}$ ), whereas tempering is usually performed in the range of $1023 \mathrm{~K}$ to $1053 \mathrm{~K}\left(750{ }^{\circ} \mathrm{C}\right.$ to $\left.780{ }^{\circ} \mathrm{C}\right) .{ }^{[1]}$

X. XU, G.D. WEST, and R.C. THOMSON are with the Department of Materials, Loughborough University, Loughborough LE11 3TU, UK. Contact email: R.C.Thomson@lboro.ac.uk J.A. SIEFERT and J.D. PARKER are with the EPRI, 1300 Harris Boulevard, Charlotte, NC 28262.

Manuscript submitted October 29, 2016.

Article published online February 8, 2018
The vast majority of Grade 92 components, such as headers or main steam piping systems, are constructed using the traditional arc welding process, such as gas tungsten arc welding, shielded metal arc welding (SMAW), or submerged arc welding (SAW). ${ }^{[2]}$ The complexity and thickness of the components specified in a thermal power plant mean that it is necessary to manufacture weldments in this steel, which require the use of multipass welding techniques. ${ }^{[2]}$

The microstructures of multipass welds can be very complex, with multiple heat treatment cycles to different peak temperatures applied to individual weld beads as a result of the manufacturing process. Therefore, in a previous work by the authors, a single-pass Grade 92 steel weld has been studied in order to fully understand the transformations that can take place in both the matrix and the resulting precipitate distribution. The microstructure in the heat-affected zone (HAZ) arising from the deposition of a single-pass weld bead was divided into three distinct regions: the completely transformed (CT) region, the partially transformed $(\mathrm{PT})$ region, and the overtempered (OT) region. ${ }^{[3]}$ These regions were linked to the peak temperature the microstructure experienced as a result of the welding cycle, such that the HAZ of an as-welded Grade 92 single-pass weld was categorized as follows: 
(1) the CT region (i.e., peak temperature $>A c_{3}$ ), in which the original matrix of the parent metal is fully reaustenitized with a complete dissolution of the pre-existing secondary precipitate particles;

(2) the PT region (i.e., peak temperature between $A c_{1}$ and $A c_{3}$ ), in which the original matrix is only partially reaustenitized together with a partial dissolution of the pre-existing precipitate particles; and

(3) the OT region (i.e., peak temperature $<A c_{1}$ ), in which the grain structure remains similar to the original matrix in the parent metal (however, the pre-existing secondary precipitate particles are coarsened during welding).

The preceding definition of the HAZ microstructure was established based on extensive microstructural observations that were obtained from the HAZ of a single-pass Grade 92 weld. The key findings reported in the previous study ${ }^{[3]}$ were as follows.

(1) Reaustenitization of the martensitic matrix in the original parent metal, upon exposure to weld thermal cycles with high heating rates, did not occur until the temperature reached values that were much higher than the $A e_{1}$ and the $A e_{3}$ temperatures [e.g., $A c_{1}: 1150\left(877^{\circ} \mathrm{C}\right) \pm 9 \mathrm{~K} ; A c_{3}$ : $1330\left(1057^{\circ} \mathrm{C}\right) \pm 30 \mathrm{~K}$, which were $\sim 85 \mathrm{~K}$ and $\sim 195 \mathrm{~K}$ higher than the $A e_{1}$ and the $A e_{3}$, respectively].

(2) In regions where the peak temperature of the weld thermal cycle was above the $A c_{3}$ temperature, the final microstructure after welding was composed of fine martensitic laths, with austenite grains approximately $50 \mu \mathrm{m}$ in size. As the peak temperature of the weld thermal cycle decreased, the presence of smaller austenite grains with finer lath substructures with a size of 10 to $20 \mu \mathrm{m}$ was observed. As the peak temperature further decreased to the intercritical range between the $A c_{1}$ and $A c_{3}$ temperatures, the final microstructure was formed as a result of partial reaustenitization of the original parent metal, as a combination of freshly formed fine martensitic laths and relatively coarser laths from the original parent metal microstructure. When the peak temperature of the weld thermal cycle was lower than the $A c_{1}$ temperature, the original grain structure of the parent metal was not significantly changed.

(3) The pre-existing precipitates in the parent metal (e.g., $\quad \mathrm{M}_{23} \mathrm{C}_{6}$ carbides and $\mathrm{MX}$ carbonitrides) started to dissolve as the peak temperature of the weld thermal cycle reached $1173 \mathrm{~K}\left(900^{\circ} \mathrm{C}\right)$, i.e., $A c_{1}+23 \mathrm{~K}$, but were not completely dissolved until the peak temperature of the weld thermal cycle reached values higher than $1373 \mathrm{~K}\left(1100{ }^{\circ} \mathrm{C}\right)$, i.e., $A c_{3}+43 \mathrm{~K}$. These pre-existing precipitates, especially the $\mathrm{M}_{23} \mathrm{C}_{6}$ carbides, were found to be coarsened slightly upon exposure to a weld thermal cycle with a peak temperature below the $A c_{1}$ temperature [e.g., $\left.1103 \mathrm{~K}\left(830^{\circ} \mathrm{C}\right) \approx A c_{1}-47 \mathrm{~K}\right]$.
(4) As the peak temperature of the weld thermal cycle increased, the $\mathrm{M}_{23} \mathrm{C}_{6}$ carbides first started dissolving as the peak temperature of weld thermal cycle reached $1173 \mathrm{~K}\left(900{ }^{\circ} \mathrm{C}\right)$ and were completely dissolved as the peak temperature reached $1273 \mathrm{~K}\left(1000^{\circ} \mathrm{C}\right)$. The MX carbonitrides, however, were stable to higher temperatures than the $\mathrm{M}_{23} \mathrm{C}_{6}$ carbides and were not completely dissolved until the peak temperature of the weld thermal cycle reached $1373 \mathrm{~K}\left(1100{ }^{\circ} \mathrm{C}\right)$. The presence of nanoscale $\mathrm{M}_{3} \mathrm{C}$ precipitates was also observed after exposure to a weld thermal cycle with a peak temperature above $1273 \mathrm{~K}\left(1000{ }^{\circ} \mathrm{C}\right)$, as a consequence of auto-tempering during the cooling phase of the weld thermal cycle.

The steep thermal gradients typically experienced in weld HAZs mean that the distances between the regions where pre-existing precipitates are completely or partially dissolved and the regions where the original parent metal microstructure was fully or partially reaustenitized were small. ${ }^{[4]}$ Therefore, it was established that an accurate description of the HAZ microstructure in Grade 92 steel welds could be obtained from classifying the HAZ into three regions (i.e., the CT-, PT-, and the OT-HAZ regions), which related to where the peak temperature of the weld thermal cycle sat in relation to the $A c_{1}$ and the $A c_{3}$ temperatures.

The purpose of this research was, therefore, to systematically investigate the microstructural distribution in the HAZ of multipass welds, in which there are accumulated influences from multiple weld thermal cycles, in order to determine if the definition of the microstructure in the HAZ of multipass welds is consistent with the preceding classification for $9 \mathrm{wt}$ pct $\mathrm{Cr}$ steel HAZ microstructures developed from simpler, single bead-on-plate experiments.

In the case of a single bead-on-plate weld, the thermal profile can be calculated using standard Rosenthal equations, ${ }^{[4]}$ and the peak temperature experienced by a particular location in the HAZ is a function of distance from the weld source and, in turn, from the weld line. The thermal history in the HAZ of a multipass weld is more complicated and the characterization of the weldment needs to include consideration of both the reheated weld metal and reheated HAZ regions. ${ }^{[4,5]}$ Each of the weld thermal cycles exposes a given region in the HAZ to a variable peak temperature and unique heating and cooling rate specific to the distance of the location from the weld source. ${ }^{[6]}$

The microstructure in the HAZ is, in turn, controlled by the thermal history resulting from the welding process. To date, the definition of the microstructure in the HAZ for these types of high alloy martensitic steels has been based on the definition of the HAZ microstructure for low-alloy ferritic/bainitic steels (e.g., Reference 7) in which the HAZ is typically classified into the coarse-grain heat-affected zone, the fine-grain heat-affected zone (FGHAZ), the intercritical heat-affected zone (ICHAZ), and the subcritical heat-affected zone regions. ${ }^{[8]}$ In addition, the existing definition of the HAZ microstructure in Grade 92 steel welds is primarily 
based on conventional, low-resolution, metallographic examination methods (e.g., References 9 and 10). However, it has been shown that microstructural factors, such as the intrinsic grain boundary properties ${ }^{[11]}$ and the spatial distribution characteristics of secondary precipitates, ${ }^{[12,13]}$ can be associated with premature creep failure that has been observed in the HAZ, for example, type IV failures, ${ }^{[14]}$ upon long-term creep exposure. ${ }^{[15,16]}$ In such cases, failure locations have been identified as being associated with both FGHAZ and ICHAZ regions. ${ }^{[18-20]}$ Indeed, difficulties remain in identifying the critical regions where type IV failures occur due to a lack of understanding about the key microstructural factors that lead to the formation of creep damage and, therefore, an accurate description of the HAZ microstructure.

The microstructural evolution within a HAZ subjected to a weld thermal cycle is a function of very high heating (and cooling) rates and relatively short times at particular peak temperatures, which do not allow thermodynamic equilibrium to be attained ${ }^{[6]}$ For example, it has been reported that the $\alpha \rightarrow \gamma$ phase transformation can be retarded upon a heating rate higher than $20 \mathrm{~K} / \mathrm{s}\left(20^{\circ} \mathrm{C} / \mathrm{s}\right) .{ }^{[17]}$ Microsegregation of alloying elements, such as those which form primary carbides such as $\mathrm{Cr}$ and $\mathrm{C}$, has also been reported in the Grade 92 steel samples after being exposed to the simulated weld thermal cycles. ${ }^{[12]}$ The precipitation and coarsening behavior of precipitates in the martensitic matrix is also likely to be altered when subjected to rapid high-temperature cycles and may lead to the formation of the metastable secondary precipitates such as $\mathrm{M}_{3} \mathrm{C}$ and
$\mathrm{M}_{2} \mathrm{X} \cdot{ }^{[18-20]}$ Limited work has been carried out to date to investigate the nonequilibrium microstructure in the HAZ of Grade 92 steel welds ${ }^{[12,21]}$; therefore, there is a need for systematic, high-resolution examination of the different regions of the HAZ in multipass Grade 92 steel welds. This research builds on earlier research to examine a single-pass bead-on-plate weld and extends the analysis to a two-pass bead-on-plate weld in order to fully define the different regions of the HAZs in multipass, thick section weldments.

\section{EXPERIMENTAL METHODOLOGIES}

\section{A. Materials and Samples}

A two-pass bead-on-plate weld was fabricated using the SMAW process on a Grade 92 pipe section under carefully controlled conditions representative of industrial processes, as shown in Figure 1(a). The chemical composition of the parent metal was experimentally measured from the samples that were obtained from the pipe by using inductively coupled plasma-optical emission spectrometry and inductively coupled plasma-mass spectrometry, presented in Table I. The selected welding consumable was $3.2 \mathrm{~mm}$ in diameter and conformed to the requirement for E9015-B9 (i.e., a Grade 91-type filler material). The two beads in the double-pass portion, as shown in Figure 1(a), were made using an identical set of welding parameters: $125 \mathrm{~A}, 22$ to $23 \mathrm{~V}$, a travel speed of 165 to $175 \mathrm{~mm} / \mathrm{min}$, and a preheat temperature of $423 \mathrm{~K}\left(150^{\circ} \mathrm{C}\right)$. The overlap of the second bead on the

Table I. Experimentally Measured Chemical Composition of the Grade 92 Parent Metal of the Double-Pass Bead-on-Plate Weld, Balance Is Fe

\begin{tabular}{lccccccccr}
\hline \multicolumn{7}{c}{ Parent Metal (Wt Pct) } \\
\hline $\mathrm{Cr}$ & $\mathrm{Mn}$ & $\mathrm{Mo}$ & $\mathrm{Nb}$ & $\mathrm{Ni}$ & $\mathrm{Si}$ & $\mathrm{V}$ & $\mathrm{W}$ & $\mathrm{C}$ & $\mathrm{B}$ \\
\hline 8.797 & 0.49 & 0.43 & 0.062 & 0.38 & 0.211 & 0.188 & 1.836 & 0.113 & 0.0041 \\
\hline $\mathrm{N}$ & $\mathrm{Al}$ & $\mathrm{Cu}$ & $\mathrm{P}$ & $\mathrm{S}$ & $\mathrm{Ca}$ & $\mathrm{Co}$ & $\mathrm{Ti}$ & $\mathrm{Zr}$ & $\mathrm{Sn}$ \\
\hline 0.045 & 0.002 & 0.189 & 0.009 & 0.008 & 0.002 & 0.015 & 0.001 & 0.004 & 0.016 \\
\hline
\end{tabular}

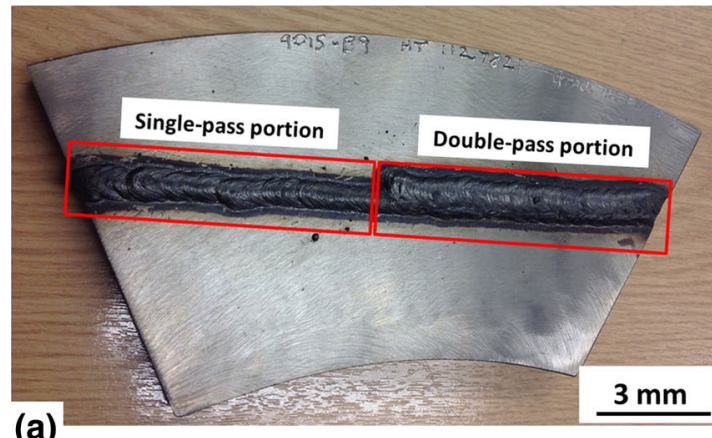

(a)

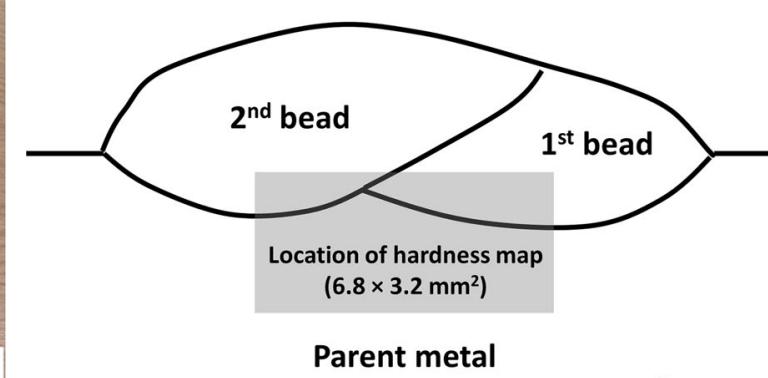

(b)
$3 \mathrm{~mm}$

Fig. 1-(a) Photograph showing a bead-on-plate weld on the Grade 92 parent metal. A second weld bead was deposited with approximately 50 pct overlap with the first bead in the double-pass portion. (b) Schematic diagram illustrating the cross section of the weld. The gray box in (b) indicates the region where the subsequent hardness mapping analysis, as shown in Fig. 13, was performed. 


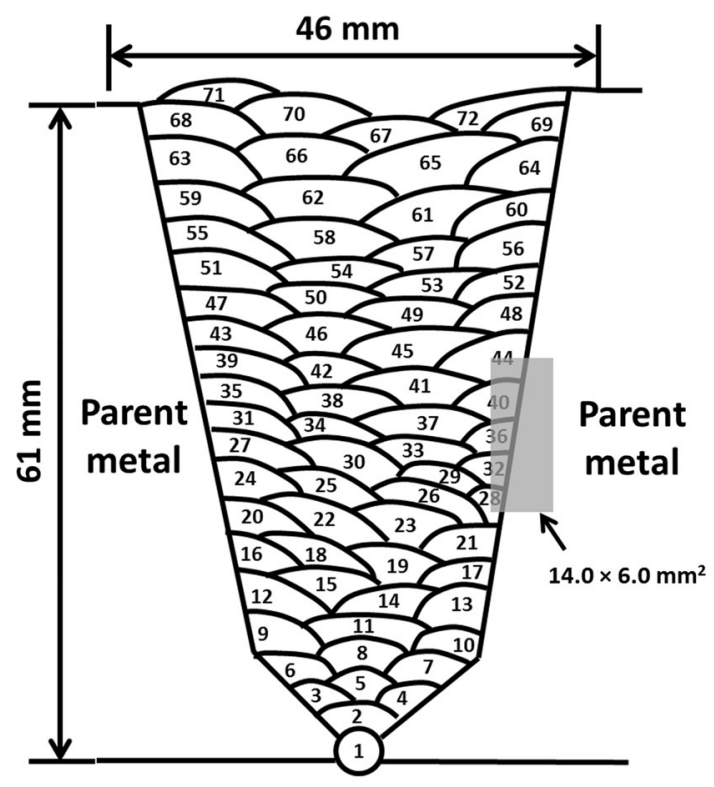

Root passes: 1 - 2

Fill passes: 3 - 72

Fig. 2-Schematic diagram illustrating the stacking structure of weld beads in a multipass SAW weld on the Grade 92 parent metal. The gray box indicates the region where the subsequent hardness mapping analysis, as shown in Fig. 15, was performed.



Fig. 3- Schematic diagram showing the dilatometry heat cycles that were performed on the Grade 92 parent metal to produce simulation materials with known thermal histories.

first bead was controlled to $\sim 50$ pct. Sections from the two-pass bead-on-plate sample were taken perpendicular to the welding direction, as illustrated in Figure 1(b).

A cross section was also examined from a 75-mm-thick Grade 92 multipass weldment. The parent metal used to fabricate the thick-section weldment was identical to that used for the two-pass bead-on-plate samples (Table I). A total of 73 weld passes were required to complete the weldment using a combination of the SMAW and SAW processes. Figure 2 illustrates the stacking structure and deposition sequence of weld beads in the multipass weld. In each process, a consumable matching to Grade 91 steel was used (i.e., either E9015-B9 for SMAW or ER90S-B9 for SAW).

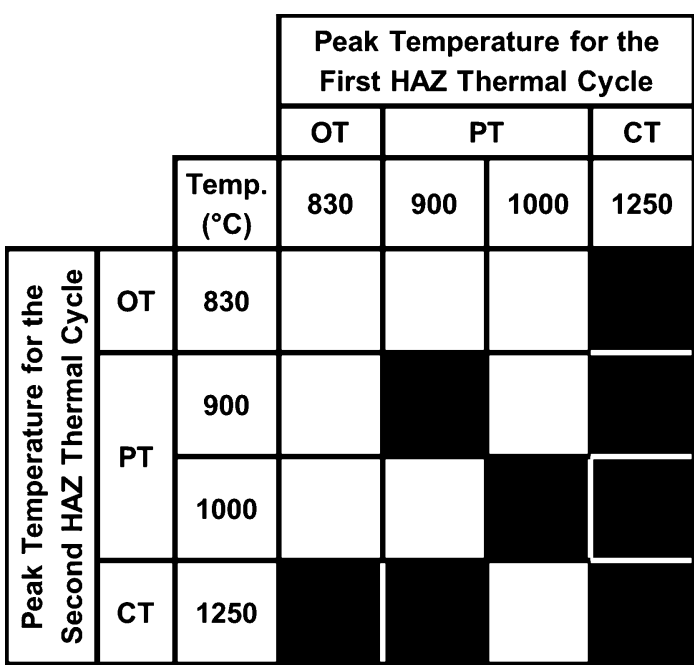

Fig. 4-Matrix of the thermal conditions for the simulated samples that were exposed to the dilatometry thermal cycles, as introduced by Fig. 3. The black boxes indicate the samples that were evaluated: OT: overtempered region, PT: partially transformed region, CT: completely transformed region. ${ }^{[3]}$

Simulated weld thermal cycle experiments were carried out using a Bahr 805 dilatometer (TA Instruments, New Castle, DE) on the parent metal samples adjacent to the welds. The samples were subjected to two sequential high-temperature thermal cycles, to either the same or different peak temperatures, in order to simulate a multipass weld thermal cycle, as shown in Figure 3 and tabulated in Figure 4. The typical peak temperatures used were the same as for the case of the single thermal cycles described in Reference 3.

Phase transformation temperatures were obtained on heating for each of the simulated peak temperatures of $1103 \mathrm{~K}, 1173 \mathrm{~K}, 1273 \mathrm{~K}$, and $1523 \mathrm{~K}\left(830^{\circ} \mathrm{C}, 900{ }^{\circ} \mathrm{C}\right.$, $1000{ }^{\circ} \mathrm{C}$, and $1250^{\circ} \mathrm{C}$ ) and for a subsequent second peak temperature of $1103 \mathrm{~K}, 1173 \mathrm{~K}, 1273 \mathrm{~K}$, and $1523 \mathrm{~K}$ $\left(830{ }^{\circ} \mathrm{C}, 900{ }^{\circ} \mathrm{C}, 1000^{\circ} \mathrm{C}\right.$, and $\left.1250{ }^{\circ} \mathrm{C}\right)$. Heating and cooling rates were carefully chosen as a balance between what was representative of industrial practice and what was practically achievable using the dilatometer. The heating rate was maintained at a constant value of $60 \mathrm{~K} / \mathrm{s}$ $\left(60{ }^{\circ} \mathrm{C} / \mathrm{s}\right)$, and the cooling rate was maintained at $30 \mathrm{~K} / \mathrm{s}$ $\left(30{ }^{\circ} \mathrm{C} / \mathrm{s}\right)$ to a temperature of $873 \mathrm{~K}\left(600^{\circ} \mathrm{C}\right)$ and was reduced to a value of $7 \mathrm{~K} / \mathrm{s}\left(7^{\circ} \mathrm{C} / \mathrm{s}\right)$ below $873 \mathrm{~K}\left(600{ }^{\circ} \mathrm{C}\right)$. The temperature to which the samples were cooled between thermal cycles was fixed at a value of $423 \mathrm{~K}$ $\left(150{ }^{\circ} \mathrm{C}\right)$ and is representative of a typical preheat temperature in the welding of $9 \mathrm{wt}$ pct Cr steels. In the case of the $1523 \mathrm{~K}\left(1250{ }^{\circ} \mathrm{C}\right)$ peak temperature simulation, the cooling rate was increased slightly to a value of $40 \mathrm{~K} / \mathrm{s}$ $\left(40{ }^{\circ} \mathrm{C} / \mathrm{s}\right)$ from the peak temperature to $873 \mathrm{~K}\left(600^{\circ} \mathrm{C}\right)$.

The $A c_{1}$ and $A c_{3}$ temperatures were determined through a comparison of plots produced from the dilation (d) vs temperature $(T)$ information and the derivative $\mathrm{d} d / \mathrm{d} T$ vs temperature, consistent with best practice guidance. ${ }^{[2]}$ The experimentally measured $A c_{1}$ and $A c_{3}$ temperatures are presented in Table II. 
Table II. $A c_{1}$ and the $A c_{3}$ Temperatures that Were Measured from the Dilation $(d)$ vs Temperature $(T)$ Information and the Derivative $\mathrm{d} d / \mathrm{d} T$ vs Temperature Plots That Were Obtained during the First and the Second Heating-Cooling Cycles of Double-Pass Simulation Thermal Cycles

\begin{tabular}{|c|c|c|c|c|}
\hline \multirow[b]{2}{*}{ Samples } & \multicolumn{2}{|c|}{ First Cycle } & \multicolumn{2}{|c|}{ Second Cycle } \\
\hline & $A c_{1}$ & $A c_{3}$ & $A c_{1}$ & $A c_{3}$ \\
\hline $1523 \mathrm{~K}+1523 \mathrm{~K}\left(1250^{\circ} \mathrm{C}+1250^{\circ} \mathrm{C}\right)$ & 894 & 1071 & 864 & 1051 \\
\hline $1523 \mathrm{~K}+1273 \mathrm{~K}\left(1250{ }^{\circ} \mathrm{C}+1000^{\circ} \mathrm{C}\right)$ & 865 & 1088 & 848 & - \\
\hline $1523 \mathrm{~K}+1173 \mathrm{~K}\left(1250{ }^{\circ} \mathrm{C}+900{ }^{\circ} \mathrm{C}\right)$ & 869 & 1087 & 856 & - \\
\hline $1523 \mathrm{~K}+1103 \mathrm{~K}\left(1250{ }^{\circ} \mathrm{C}+830^{\circ} \mathrm{C}\right)$ & 838 & 1086 & - & - \\
\hline $1103 \mathrm{~K}+1523 \mathrm{~K}\left(830^{\circ} \mathrm{C}+1250^{\circ} \mathrm{C}\right)$ & - & - & 833 & 1064 \\
\hline $1173 \mathrm{~K}+1523 \mathrm{~K}\left(900{ }^{\circ} \mathrm{C}+1250^{\circ} \mathrm{C}\right)$ & - & - & 825 & 1091 \\
\hline $1273 \mathrm{~K}+1273 \mathrm{~K}\left(1000^{\circ} \mathrm{C}+1000^{\circ} \mathrm{C}\right)$ & 880 & - & 822 & - \\
\hline $1173 \mathrm{~K}+1173 \mathrm{~K}\left(900^{\circ} \mathrm{C}+900^{\circ} \mathrm{C}\right)$ & 886 & - & 855 & - \\
\hline
\end{tabular}

\section{B. Hardness Test and Microstructural Characterization}

Hardness mapping was performed on cross sections taken from the two-pass bead-on-plate weld and the thick-section, multipass weld using a Struers Durascan 70 (Struers Ltd. Unit 11 Evolution @ the AMP, Whittle Way, Rotherham, Catcliffe) automated hardness testing system. A Vickers indenter (Struers Ltd. Unit 11 Evolution@ the AMP, Whittle Way, Rotherham, Catcliffe), using a test load of $0.2 \mathrm{~kg}$ and a uniform spacing of $0.10 \mathrm{~mm}$, was used. The area was chosen to ensure an accurate and appropriate representation of the hardness across the weld metal, HAZ regions, and parent metal. The approximate area that was examined is indicated in Figures 1(b) and 2. The hardnesses of the simulated HAZ samples were measured using an identical procedure for consistency, although the total number of indents was limited to 100 per sample.

The samples for microstructural analyses were prepared using conventional metallographic preparation procedures. A final, extended chemomechanical polishing step using a $0.02-\mu \mathrm{m}$ colloidal silica suspension was applied to eliminate the surface deformations that were introduced by the abrasive polishing stages.

An Nova 600 Nanolab dual beam (Thermo Fisher Scientific, Hillsboro, OR) focused ion beam field emission gun scanning electron microscope was used to collect the electron backscatter diffraction (EBSD) data from the matrix, and ion-beam-induced secondary electron imaging was used to evaluate the distribution of precipitate particles. EBSD maps were collected using an EDAX Hikari camera (EDAX Inc., Mahwah, NJ), at an accelerating voltage of $20 \mathrm{kV}$ and a nominal beam current of $24 \mathrm{nA}$. Two approaches were taken to optimize the analysis:

(1) A large area EBSD map was collected with a size of $1 \times 1 \mathrm{~mm}^{2}$ using a step size of $2 \mu \mathrm{m}$. This information was used to provide an overview of the grain structure present in each of the investigated weldments.

(2) A more detailed set of data was collected to perform an analysis of the prior austenite grain (PAG) and subgrain structure at higher magnifications (i.e., $200 \times 200 \mu \mathrm{m}^{2}$ and $50 \times 50 \mu \mathrm{m}^{2}$ for
PAG and substructure analyses, respectively) using a step size of $1 \mu \mathrm{m}$ (for PAG structure) or $0.1 \mu \mathrm{m}$ (for subgrain structure).

Ion-beam-induced secondary electron micrographs were collected from the identical regions in which the EBSD analyses were performed to determine the distribution of precipitates. The ion beam images were collected using an accelerating voltage of $30 \mathrm{kV}$, a nominal beam current of $50 \mathrm{pA}$, and $\mathrm{XeF}_{2}$ gas flowing to enhance the contrast differential between the particles and the matrix. The precipitates, which were visible in the ion-beam-induced secondary electron micrographs, are predominantly $\mathrm{M}_{23} \mathrm{C}_{6}$ carbides, while finer $\mathrm{M}_{2} \mathrm{X}$ and $\mathrm{MX}$ precipitates were only rarely, positively identified using this technique due to the relative diameters of the different particle types (i.e., 100 to $200 \mathrm{~nm}$ for $\mathrm{M}_{23} \mathrm{C}_{6}$ and $\sim 30 \mathrm{~nm}$ for $\mathrm{M}_{2} \mathrm{X}$ and MX).

Analysis of the secondary precipitate particles in the simulated HAZ samples was performed using carbon extraction replicas. Sample surfaces were first etched in Villela's reagent (1 g picric acid, $5 \mathrm{~mL}$ hydrochloric acid, and $100 \mathrm{~mL}$ ethanol) for approximately 10 seconds and then a thin film of carbon was deposited using a Quorum Technologies Q150T ES (Quorum Technologies Ltd, Laughton, East Sussex, UK) coating system. The carbon film was electrolytically removed in a solution of 10 pct hydrochloric acid in methanol and rinsed first in methanol followed by deionized water. The replicas were collected on standard copper grids for subsequent transmission electron microscopy (TEM) analysis. The precipitates on each of the replicas were chemically analyzed using energy-dispersive X-ray spectroscopy (EDX) in an Tecnai F20 (Thermo Fisher Scientific, Hillsboro, OR) transmission electron microscope equipped with an Oxford Instruments X-Max $80^{\mathrm{N}}$ TLE EDS (Oxford Instruments plc, Abingdon, Oxfordshire, UK) system. The precipitates were identified using selected area electron diffraction (SAED) in a JEOL* JEM 2000FX transmission electron microscope.

*JEOL is a trademark of Japan Electron Optics Ltd., Tokyo. 

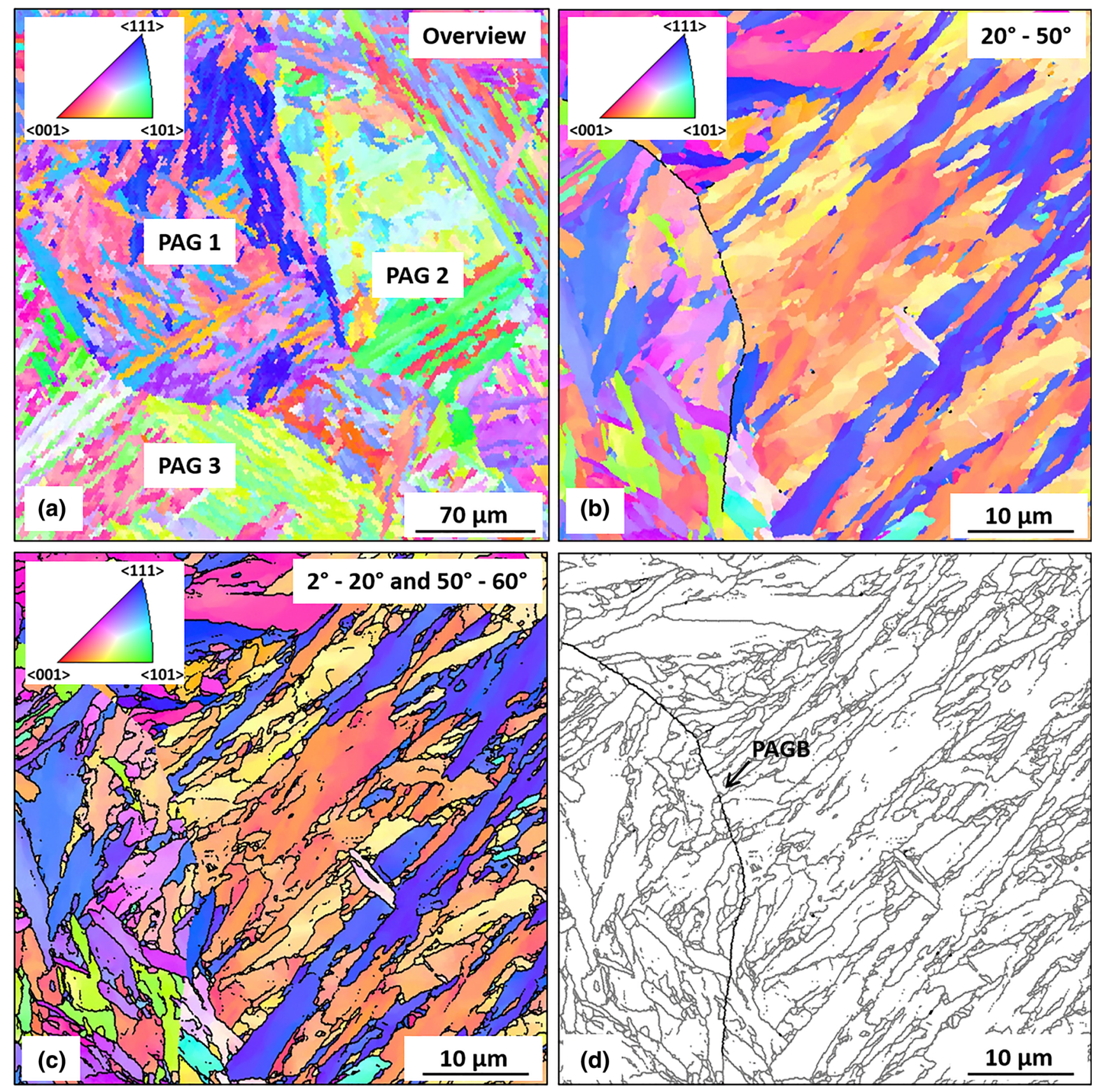

$2^{\circ}-20^{\circ}$ and $50^{\circ}-60^{\circ}(3950 \mu \mathrm{m})$

\section{$-20^{\circ}-50^{\circ}(61 \mu \mathrm{m})$}

Fig. 5- (a) EBSD grain orientation map providing an overview of the grain structure in the parent metal. Overlaid images of the EBSD grain orientation and $(b)$ and $(c)$ the EBSD grain boundary maps in which the outlines of (b) the 20 to 50 deg and (c) the 2 to 20 and the 50 to 60 deg boundaries are presented. (d) EBSD grain boundary map in which the outlines of the 20 to 50 deg (black) and the 2 to 20 and 50 to 60 deg (gray) boundaries are both shown.

\section{RESULTS}

\section{A. The Microstructure of the Grade 92 Parent Metal}

An overview of the grain structure in the parent metal is presented in Figure 5. Overlaid images of the EBSD grain orientation and the EBSD grain boundary maps are also included.
A tempered martensitic grain structure was observed in the parent metal of the two-pass bead-on-plate weld. The sizes of the PAGs in the parent metal were generally larger than $200 \mu \mathrm{m}$ and the lathlike grains inside the PAGs had a width of less than $20 \mu \mathrm{m}$. The overlaid images of EBSD grain orientation and grain boundary maps illustrate that the boundaries of the lathlike grains 



$-2^{\circ}-20^{\circ}-20^{\circ}-50^{\circ}-50^{\circ}-60^{\circ}$

Fig. 6-(a) EBSD grain boundary map and $(b)$ and $(c)$ ion-beam-induced secondary electron micrographs that were obtained from the identical region in the parent metal. (b) Grain structure and (c) precipitate distribution were revealed using different ion beam doses.

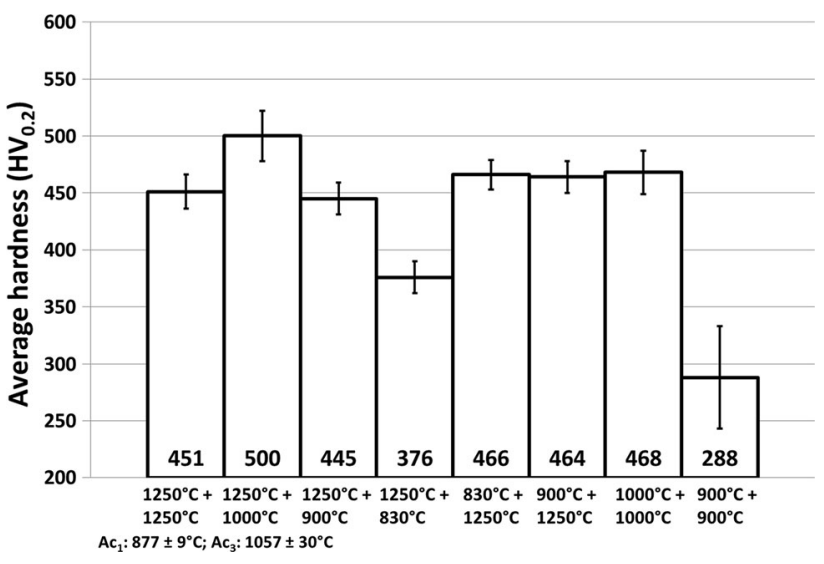

Fig. 7-Graph showing the average hardness of the parent metal samples after exposure to the simulations of double-pass weld thermal cycles. A minimum of 100 measurements were conducted on each sample.

within the martensitic substructure are predominantly in the ranges of 2 to 20 and 50 to $60 \mathrm{deg}$, whereas a significant proportion of the PAGBs (prior austenite grain boundary) exhibited a misorientation within the range of 20 to $50 \mathrm{deg}$. Similar observations have been reported in the literature, in which the misorientation of martensitic substructure boundaries was determined to be in the range of 2 to 20 and 50 to $60 \mathrm{deg}$ due to the presence of a Kurdjumov-Sachs orientation relationship between the martensite and parent austenite phases. ${ }^{[22]}$ However, the misorientation of a significant fraction of the PAGBs was, found to be in the range of 20 to $50 \mathrm{deg}$, due to the fact that the misorientation of the PAGBs follows a Mackenzie-type distribution of grain boundary misorientation for nontextured cubic structures. ${ }^{[23]}$ Although some segments of the PAGBs in this case were also observed to have a misorientation in the range of 2 to 20 and 50 to $60 \mathrm{deg}$, the lengths of these segments were negligible compared to the length of the substructure boundaries (Figure 5(d)). It was, thus, considered that the classification of boundaries with distinctly different misorientation distribution characteristics, ${ }^{[3]}$ in combination with quantitative measurements of the lengths of boundaries ${ }^{[12]}$ in different misorientation ranges (e.g., 2 to 20, 20 to 50, and 50 to $60 \mathrm{deg}$ ), could effectively indicate the variation of the martensitic substructure and PAG structure properties as a function of the different weld thermal cycles experienced.

The distribution characteristics of the secondary precipitate particles in the parent metal were analyzed using EBSD mapping analysis and ion-beam-induced secondary electron imaging. Figure 6 shows the EBSD grain boundary map and the ion-beam-induced secondary electron micrographs that were collected from an identical region in the parent metal. The observed boundaries in Figure 6 were predominately high-angle boundaries of 2 to 20 and 50 to $60 \mathrm{deg}$ and observed to be highly decorated by precipitate particles with a size of approximately $200 \mathrm{~nm}$.

\section{B. Phase Transformation Temperatures in Simulated HAZ Experiments}

In this section, the simulated thermal cycles are referred to by the peak temperature experienced in successive thermal cycles. Therefore, the description " $1523 \mathrm{~K}+1523 \mathrm{~K}\left(1250{ }^{\circ} \mathrm{C}+1250{ }^{\circ} \mathrm{C}\right)$ " refers to the fact that the peak temperature for the first cycle was $1523 \mathrm{~K}\left(1250{ }^{\circ} \mathrm{C}\right)$ and that for the second cycle was also $1523 \mathrm{~K}\left(1250^{\circ} \mathrm{C}\right)$.

The values of the $A c_{1}$ and the $A c_{3}$ temperatures of the parent metal were measured from a single heating-cooling cycle, which simulates the weld thermal history in the HAZ of a single-pass weld. The $A c_{1}$ and the $A c_{3}$ temperatures were, thus, measured at $1150 \mathrm{~K}\left(877{ }^{\circ} \mathrm{C}\right)$ $\pm 9 \mathrm{~K}$ and $1330 \mathrm{~K}\left(1057^{\circ} \mathrm{C}\right) \pm 30 \mathrm{~K}$, respectively. ${ }^{[3]}$ The transformation temperatures were also determined from the double-pass simulation thermal cycles in the dilatometer, as illustrated in Table II.

The mean hardness values of the simulated HAZ samples are shown in Figure 7, and the statistics for each sample are detailed in Table III. The hardness value for a single thermal cycle with a peak temperature 


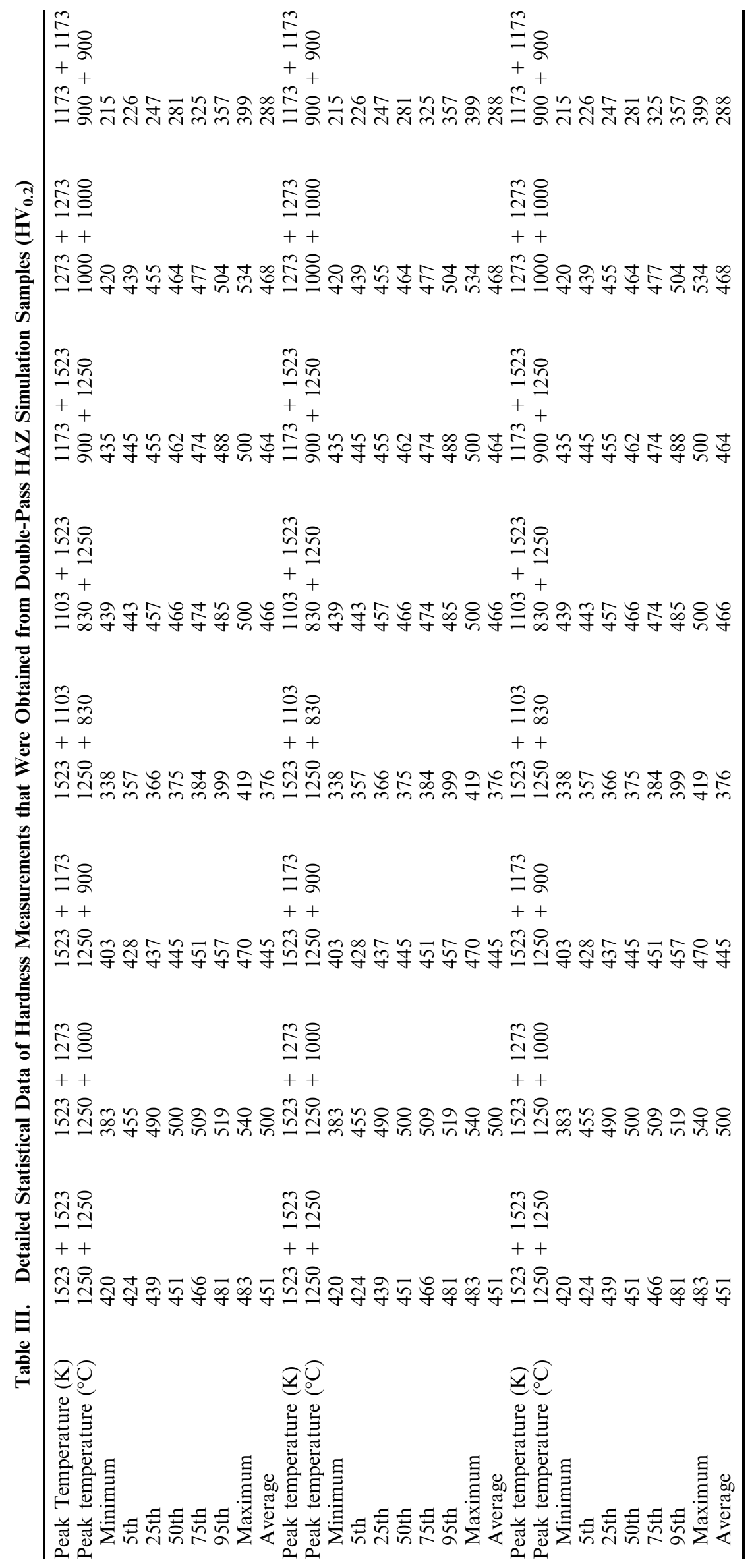




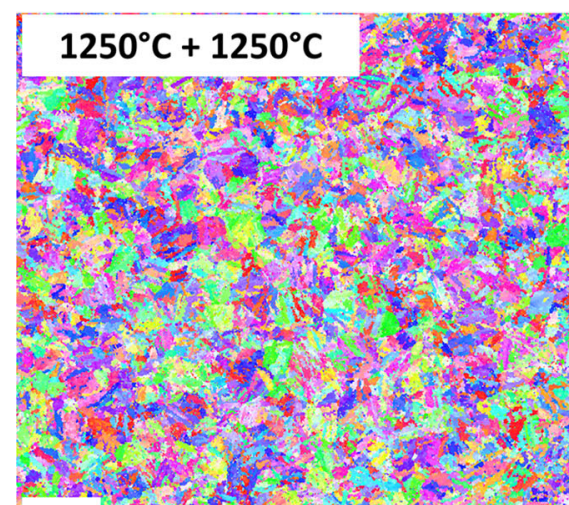

(a)

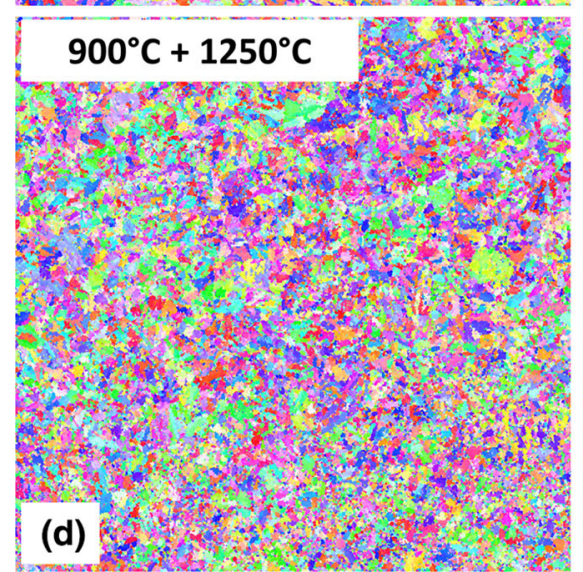

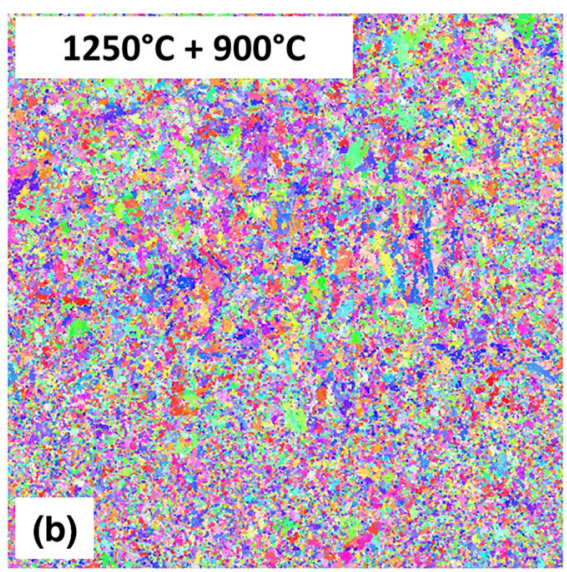
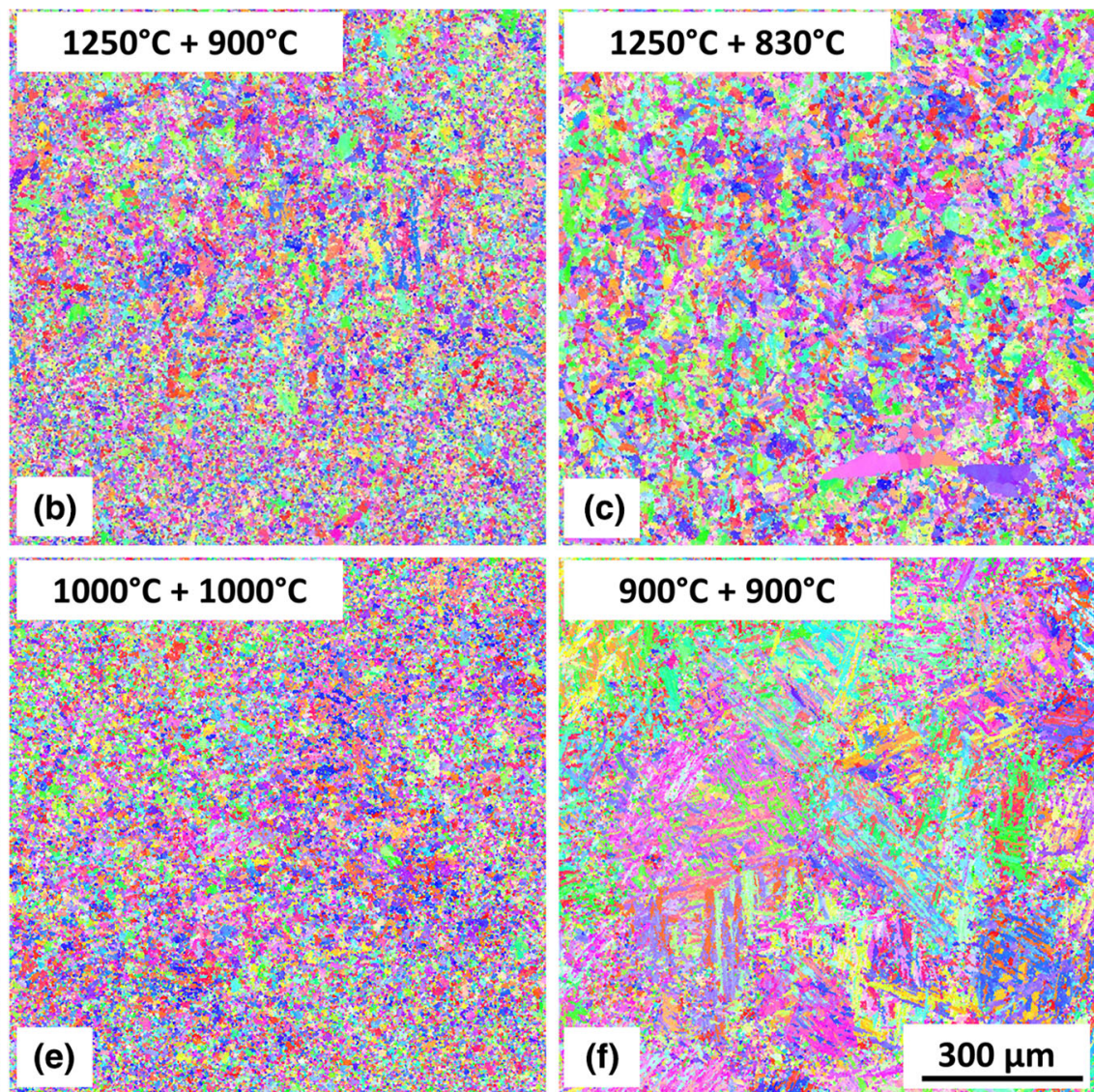

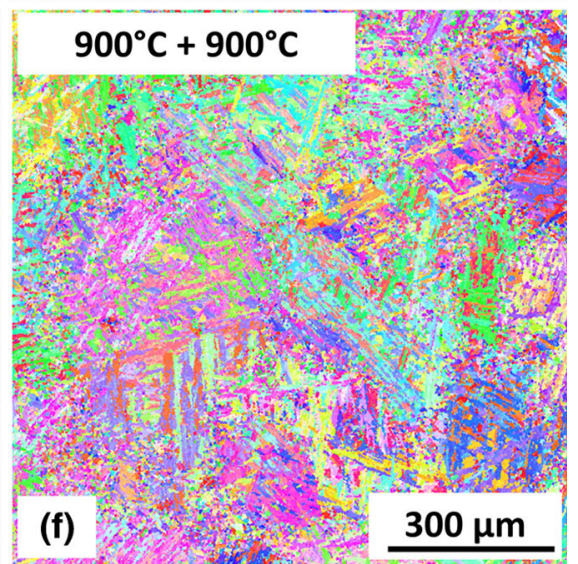

Fig. 8-EBSD grain orientation maps showing the grain structures in the HAZ-simulated materials after the simulations of the double-pass weld thermal cycles with various peak temperatures for the first and second cycle respectively: (a) $1523 \mathrm{~K}+1523 \mathrm{~K},($ b) $1523 \mathrm{~K}+1173 \mathrm{~K}$, (c) $1573 \mathrm{~K}+1103 \mathrm{~K},($ d $) 1173 \mathrm{~K}+1573 \mathrm{~K},($ e) $1273 \mathrm{~K}+1273 \mathrm{~K}$ and $(f) 1173 \mathrm{~K}+1173 \mathrm{~K}$.

of $1523 \mathrm{~K}\left(1250{ }^{\circ} \mathrm{C}\right)$ was found to be $\sim 470 \mathrm{HV}_{0.2} \cdot{ }^{[3]}$ The influence of the second thermal cycle was found to be as follows.

(1) The $1523 \mathrm{~K}+1523 \mathrm{~K}\left(1250^{\circ} \mathrm{C}+1250^{\circ} \mathrm{C}\right)$ cycle did not markedly change the observed hardness values.

(2) In the $1523 \mathrm{~K}+1273 \mathrm{~K}\left(1250{ }^{\circ} \mathrm{C}+1000{ }^{\circ} \mathrm{C}\right)$ cycle, the hardness was seen to increase, which is consistent with the refined grain structure observed as a consequence of the second thermal cycle being between $A c_{1}$ and $A c_{3}$.

(3) The $1523 \mathrm{~K}+1173 \mathrm{~K}\left(1250{ }^{\circ} \mathrm{C}+900{ }^{\circ} \mathrm{C}\right)$ cycle did not markedly change the observed hardness values.

(4) The $1523 \mathrm{~K}+1103 \mathrm{~K}\left(1250{ }^{\circ} \mathrm{C}+830{ }^{\circ} \mathrm{C}\right)$ cycle resulted in a decrease in the hardness of $\sim 75 \mathrm{HV}$, to a value of $376 \mathrm{HV}_{0.2}$.

In samples $1103 \mathrm{~K}+1523 \mathrm{~K}\left(830{ }^{\circ} \mathrm{C}+1250{ }^{\circ} \mathrm{C}\right)$ and $1173 \mathrm{~K}+1523 \mathrm{~K}\left(900{ }^{\circ} \mathrm{C}+1250{ }^{\circ} \mathrm{C}\right)$, the hardness values (i.e., $\sim 465 \mathrm{HV}_{0.2}$ ) were similar to the single $1523 \mathrm{~K}$ $\left(1250{ }^{\circ} \mathrm{C}\right)$ thermal cycle. For the $1273 \mathrm{~K}+1273 \mathrm{~K}$ $\left(1000{ }^{\circ} \mathrm{C}+1000{ }^{\circ} \mathrm{C}\right)$ cycle, the hardness was not significantly different $\left(468 \mathrm{HV}_{0.2}\right)$ from that of the single $1523 \mathrm{~K}\left(1250{ }^{\circ} \mathrm{C}\right)$ thermal cycle. The $1173 \mathrm{~K}+1173 \mathrm{~K}$ $\left(900{ }^{\circ} \mathrm{C}+900{ }^{\circ} \mathrm{C}\right)$ sample exhibited the lowest hardness values in these experiments at $288 \mathrm{HV}_{0.2}$.
The grain structures in the dilatometry simulated parent metal samples were characterized by using EBSD mapping analysis. Figure 8 shows the EBSD grain orientation maps that were collected from selected double-cycle HAZ simulations.

In the $1523 \mathrm{~K}+1523 \mathrm{~K}\left(1250{ }^{\circ} \mathrm{C}+1250{ }^{\circ} \mathrm{C}\right)$ sample, the grain structure in the simulated parent metal sample is predominantly composed of PAGs with a size of approximately $50 \mu \mathrm{m}$, whereas the $1523 \mathrm{~K}+1173 \mathrm{~K}$ $\left(1250{ }^{\circ} \mathrm{C}+900^{\circ} \mathrm{C}\right)$ begins to show a duplex grain structure composed of both PAGs that are less than 20 $\mu \mathrm{m}$ and approximately $50 \mu \mathrm{m}$ in diameter. The $1523 \mathrm{~K}+$ $1103 \mathrm{~K}\left(1250^{\circ} \mathrm{C}+830^{\circ} \mathrm{C}\right)$ retains a grain structure that is predominantly composed of PAGs with a size of approximately $50 \mu \mathrm{m}$. In the simulations where the second thermal cycle was $1523 \mathrm{~K}\left(1250^{\circ} \mathrm{C}\right)$, the PAG size was $\sim 50 \mu \mathrm{m}$. The grain structure in the $1273 \mathrm{~K}+$ $1273 \mathrm{~K}\left(1000{ }^{\circ} \mathrm{C}+1000{ }^{\circ} \mathrm{C}\right)$ sample was found to be predominantly composed of grains with a size of $<20$ $\mu \mathrm{m}$. The $1173 \mathrm{~K}+1173 \mathrm{~K}\left(900{ }^{\circ} \mathrm{C}+900{ }^{\circ} \mathrm{C}\right)$ sample was composed of a duplex grain structure in which very fine PAGs with a size of less than $10 \mu \mathrm{m}$ were distributed along the pre-existing PAGBs $(\sim 200 \mu \mathrm{m}$ in diameter $)$ in the original matrix of the parent metal.

Ion-beam-induced secondary electron imaging was also performed on the parent metal samples after each of the double-simulated HAZ thermal cycles to 

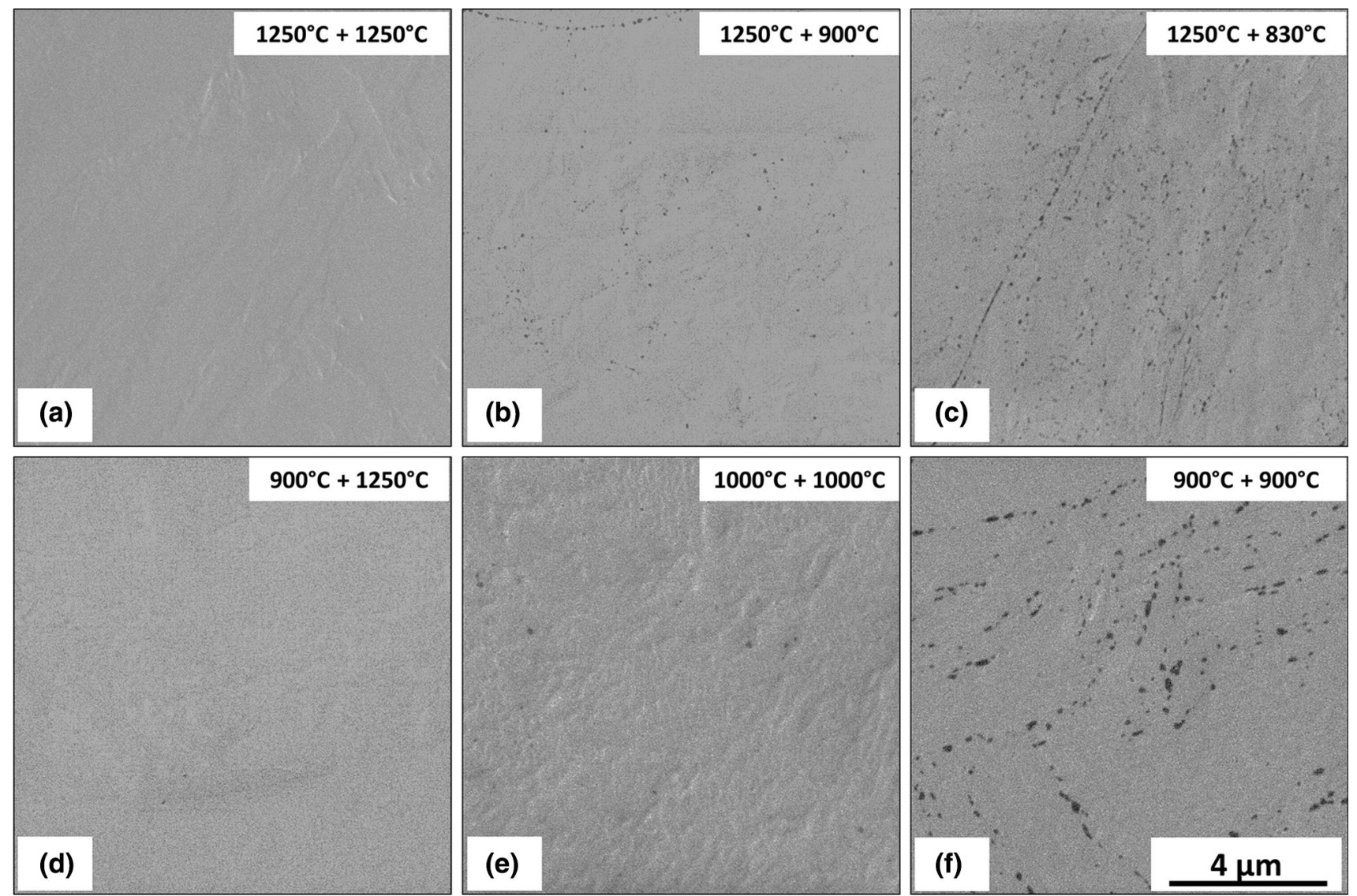

Fig. 9-Ion-beam-induced secondary electron micrographs showing secondary precipitate particles after the simulated double-pass weld thermal cycles with various peak temperatures for the first and second cycle respectively: (a) $1523 \mathrm{~K}+1523 \mathrm{~K}$, (b) $1523 \mathrm{~K}+1173 \mathrm{~K}$, (c) $1573 \mathrm{~K}+1103 \mathrm{~K},(d) 1173 \mathrm{~K}+1573 \mathrm{~K},(e) 1273 \mathrm{~K}+1273 \mathrm{~K}$ and $(f) 1173 \mathrm{~K}+1173 \mathrm{~K}$
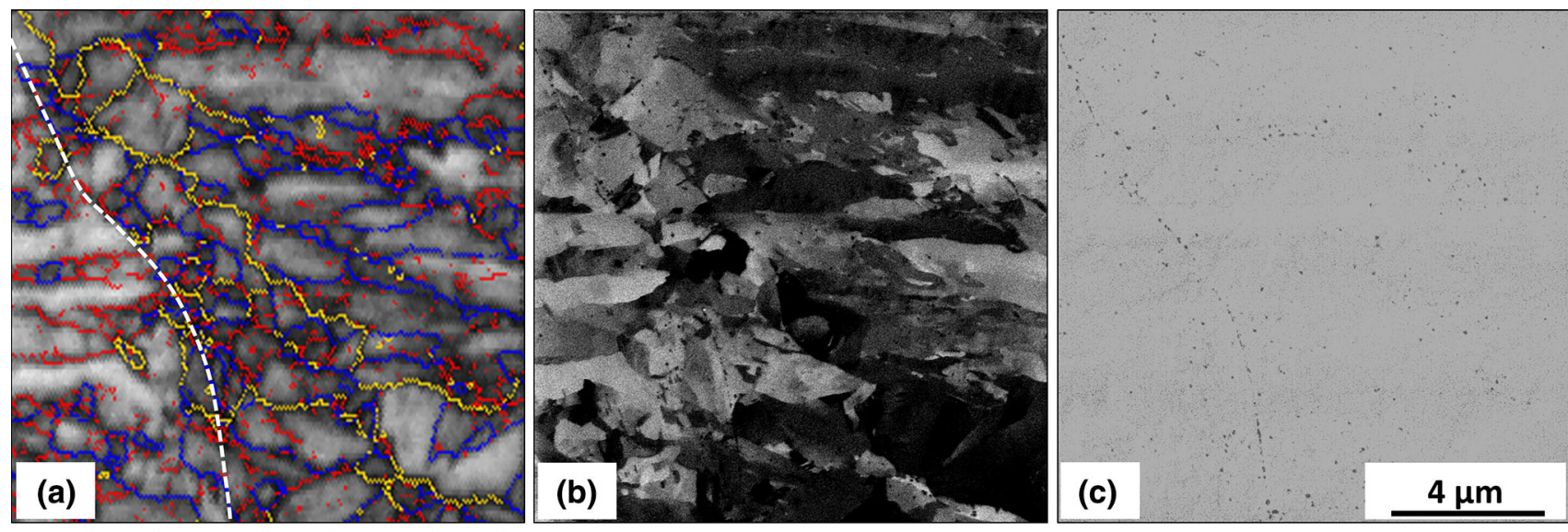

$-2^{\circ}-20^{\circ}-20^{\circ}-50^{\circ}-50^{\circ}-60^{\circ}$

Fig. 10 - (a) EBSD grain boundary map and $(b)$ and $(c)$ ion-beam-induced secondary electron micrographs that were collected from identical regions after double-pass weld thermal cycle with peak temperatures of $1523 \mathrm{~K}+1173 \mathrm{~K}\left(1250{ }^{\circ} \mathrm{C}+900{ }^{\circ} \mathrm{C}\right)$. The white dashed line in (a) indicates the location of a stringer of secondary precipitate particles, as observed in (c).

investigate the distribution characteristics of secondary precipitate particles. Figure 9 shows selected results from the ion-beam-induced secondary electron micrographs.
The presence of precipitates was not observed in the simulated parent metal samples that were exposed to a peak temperature of $1523 \mathrm{~K}\left(1250{ }^{\circ} \mathrm{C}\right)$ in the second thermal cycle (Figures 9(a) and (d)). In the simulated 

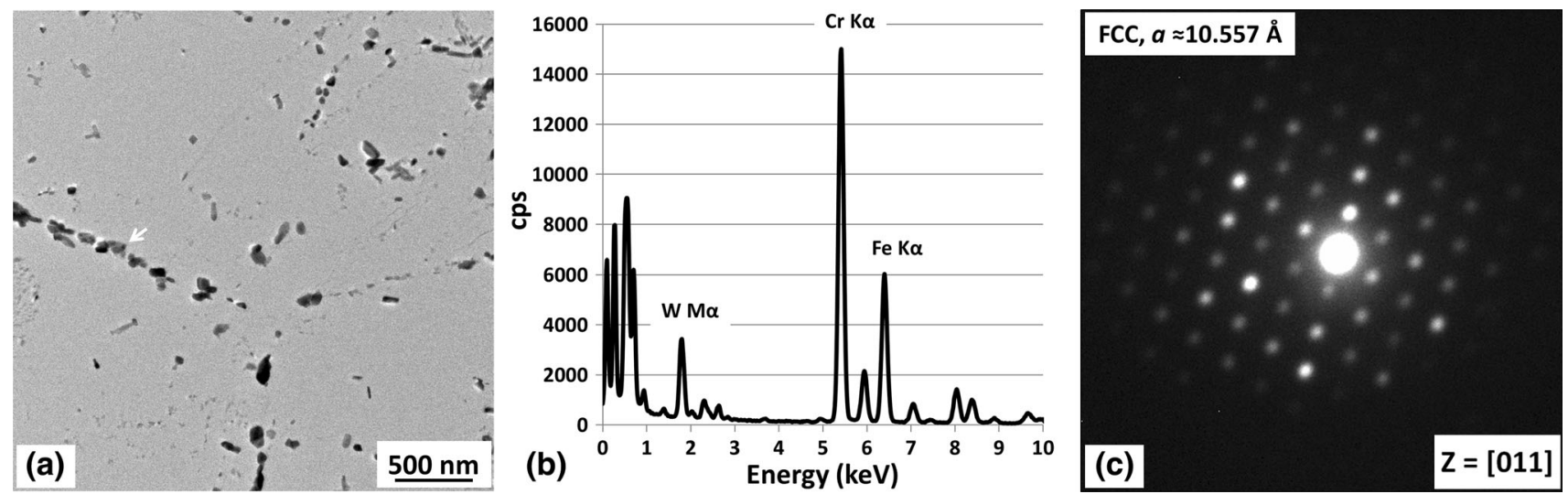

Fig. 11-(a) TEM bright-field micrograph showing the secondary precipitate particles in the parent metal sample that was exposed to the simulation of the double-pass weld thermal cycle with peak temperatures of $1523 \mathrm{~K}+1103 \mathrm{~K}\left(1250{ }^{\circ} \mathrm{C}+830{ }^{\circ} \mathrm{C}\right)$. (b) EDX spectrum and $(c)$ SAEDP that were obtained from a particle, as indicated by the white arrow in (a).

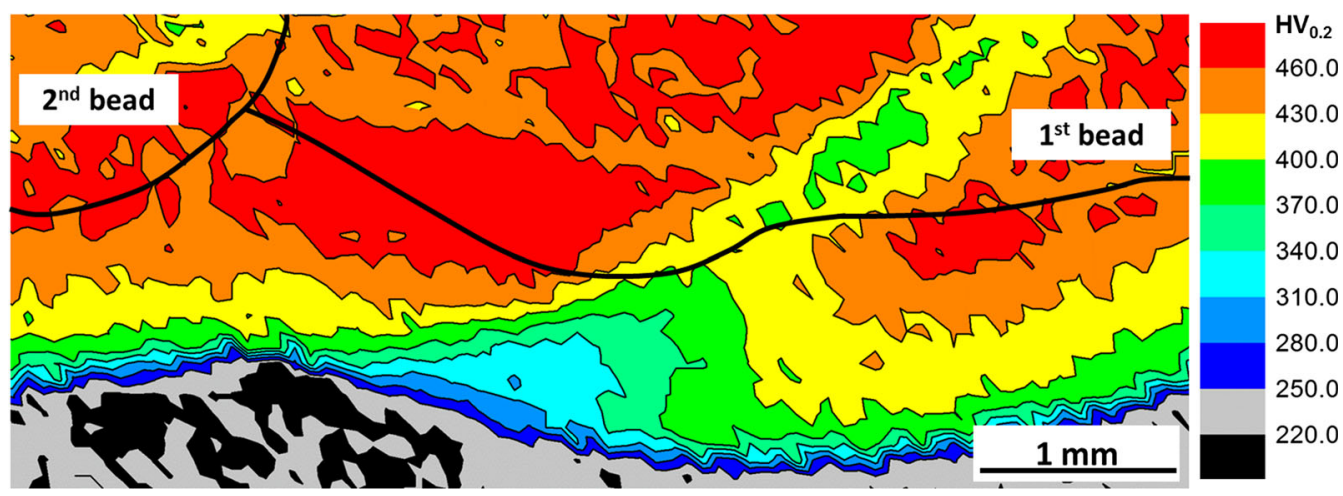

Fig. 12-Large-scale hardness map showing the variation of hardness in a double-pass bead-on-plate weld on a Grade 92 parent metal. The solid line indicates the weld line.

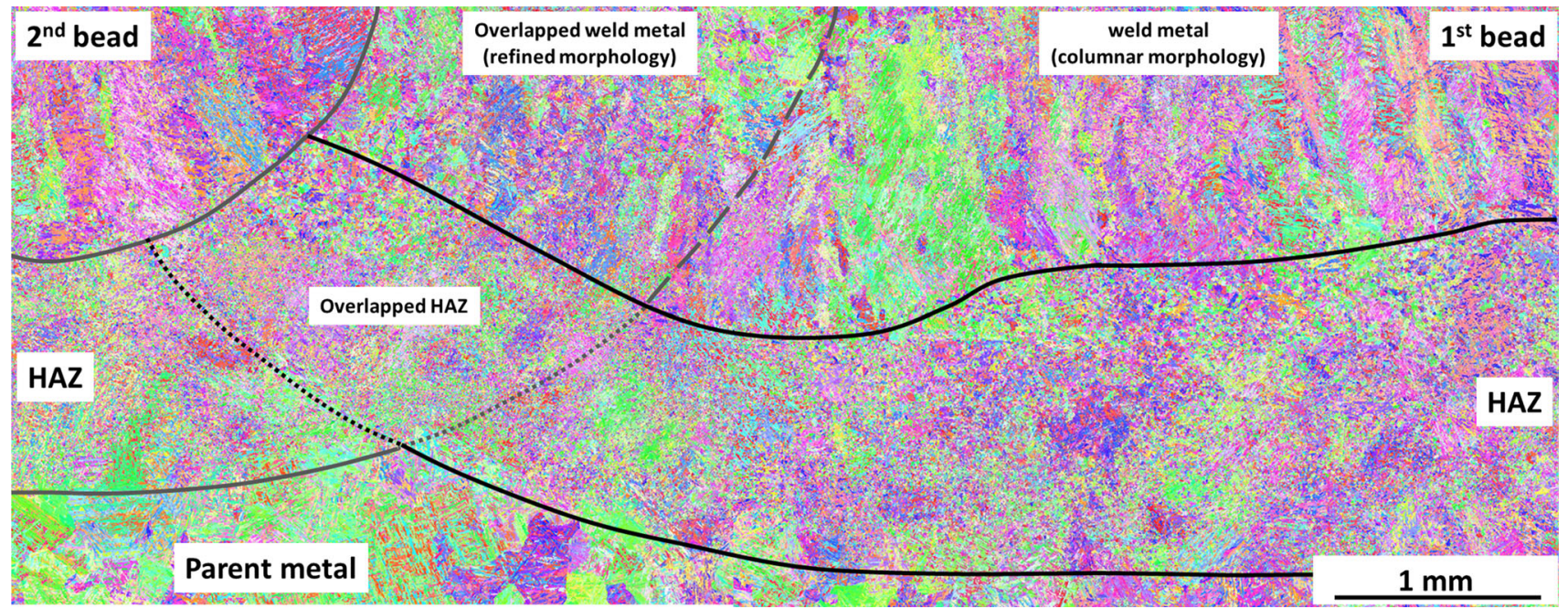

Fig. 13-Large-scale montage of EBSD grain orientation maps indicating different regions in a double-pass bead-on-plate weld on the Grade 92 parent metal. The region where the montage of EBSD maps was obtained is identical to the region where the hardness map, as shown in Fig. 13, was collected. The solid lines indicate the weld line and the boundary of the HAZ. The boundaries of the overlapped regions in the weld metal and the HAZ are indicated by dashed lines. 


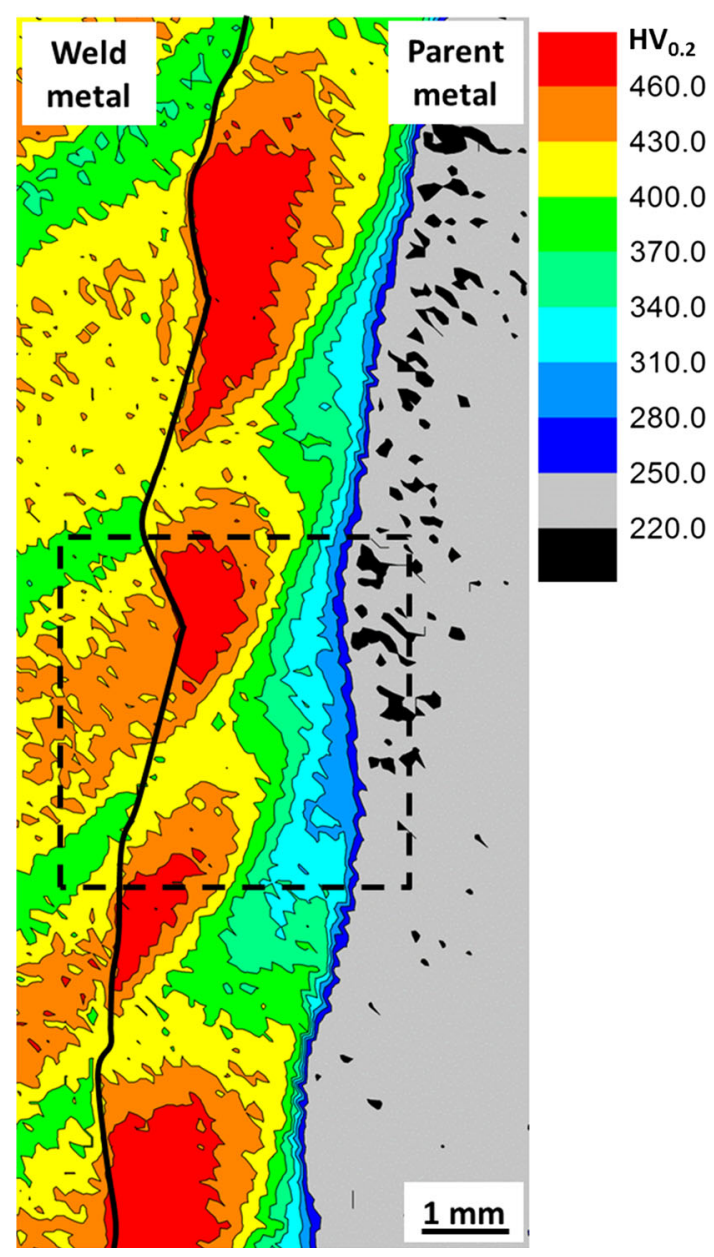

Fig. 14-Large-scale hardness map showing the variation of hardness in an as-welded multipass SAW weld on a Grade 92 steam pipe. The region where the hardness map was collected is indicated by the gray box in Fig. 2. The solid line and the dashed box indicate the weld line and the region where the subsequent grain structure analyses, as shown in Fig. 16, were performed, respectively.

HAZ samples $1523 \mathrm{~K}+1173 \mathrm{~K}\left(1250{ }^{\circ} \mathrm{C}+900{ }^{\circ} \mathrm{C}\right)$ and $1523 \mathrm{~K}+1103 \mathrm{~K}\left(1250{ }^{\circ} \mathrm{C}+830{ }^{\circ} \mathrm{C}\right)$, the presence of very fine precipitates with a size of less than $100 \mathrm{~nm}$ was observed (Figures 9(b) and (c)). In the simulated parent metal samples that were exposed to intercritical peak temperatures between the $A c_{1}$ and the $A c_{3}$ temperatures, samples $1273 \mathrm{~K}+1273 \mathrm{~K}\left(1000{ }^{\circ} \mathrm{C}+\right.$ $\left.1000{ }^{\circ} \mathrm{C}\right)$ and $1173 \mathrm{~K}+1173 \mathrm{~K}\left(900{ }^{\circ} \mathrm{C}+900{ }^{\circ} \mathrm{C}\right)$, the presence of undissolved precipitates having a size of approximately $200 \mathrm{~nm}$ was observed (e.g., Figures 9(e) and (f)).

EBSD mapping analysis and ion-beam-induced secondary electron imaging were performed in identical regions to directly investigate the relationship between precipitates and the grain structure. Figure 10 shows the EBSD grain boundary map and the ion-beam-induced secondary electron micrographs that were collected from an identical region in the $1523 \mathrm{~K}+1173 \mathrm{~K}$ $\left(1250{ }^{\circ} \mathrm{C}+900{ }^{\circ} \mathrm{C}\right)$ simulated sample.
The secondary precipitate particles that were detected in the region of analysis were found to be predominantly distributed on the martensitic substructure boundaries and PAGBs. A "stringer" of precipitates was observed and was not directly correlated with the detected grain boundaries.

The precipitates in the simulated $1523 \mathrm{~K}+1173 \mathrm{~K}$ $\left(1250{ }^{\circ} \mathrm{C}+900{ }^{\circ} \mathrm{C}\right) \mathrm{HAZ}$ sample were extracted using a carbon extraction replica technique for chemical and crystallographic analyses. Figure 11 shows a TEM bright-field micrograph of these particles and the representative EDX spectrum and SAEDP that were collected from the selected particles of interest. The chemical composition and the lattice structure of a representative particle from this array were found to be consistent with it being an $\mathrm{M}_{23} \mathrm{C}_{6}$ carbide. ${ }^{\text {24] }}$

\section{The Microstructure in the HAZ of a Two-Pass Bead-on-Plate Grade 92 Weld}

The hardness variation in the two-pass bead-on-plate weld is provided in Figure 12 as a color hardness plot. The measured hardness in the weld metal can be seen to be generally higher than $430 \mathrm{HV}_{0.2}$, and in the parent material, the hardness is consistently within the range of 220 to $250 \mathrm{HV}_{0.2}$. The partially transformed region, completely transformed region, and variations on these zones due to the second weld thermal cycle show a range of hardness values from a maximum of $\sim 460 \mathrm{HV}_{0.2}$ to $\sim 310 \mathrm{HV}_{0.2}$. The region between the unaffected parent material and the transformed regions in the HAZ, known as the overtempered region, exhibited a drop in hardness values to a minimum of $\sim 205 \mathrm{HV}_{0.2}$.

An overview of grain structure in the two-pass bead-on-plate weld was obtained using EBSD. Figure 13 shows a large-scale montage of the EBSD grain orientation maps that were collected from exactly the same regions where the hardness map, as shown in Figure 12, was obtained.

Starting in the unaffected parent material, the PAG structure is observed to be quite coarse and contains a high density of subgrain boundaries. The grain structure then becomes far more complex in the HAZ. In the regions adjacent to the unaffected parent material, the PAG size is observed to be $\sim 20 \mu \mathrm{m}$ in diameter, whereas near the fusion line, this value increases to 50 to $100 \mu \mathrm{m}$. In the overlapped HAZ region between the weld beads, the PAG structure was dominated by grains of $\sim 50 \mu \mathrm{m}$ in diameter. A coarse, columnar grain structure was observed in the weld metal in the regions away from the overlapping regions between the two weld beads. In the overlapped region of the deposited weld metal, a refined grain structure was observed.

\section{The Microstructure in the HAZ of a Multipass $S A W$ Weld from a Grade 92 Steam Pipe}

The variation of hardness in the multipass SAW weld sample was characterized by using hardness mapping, as shown in Figure 14. The hardness ranges for each of the weld metal, HAZ, overtempered, and parent metal 
constituents were found to be similar to that previously detailed for the two-pass bead-on-plate weld sample.

An overview of the grain structure was obtained by using EBSD mapping analysis across the multipass SAW weld. Figure 15 shows a large-scale montage of EBSD grain orientation maps that were obtained from regions of the weld metal, the HAZ, and the parent metal.

The grain structures in regions 1 through 6 from the HAZ of the multipass SAW weld were characterized by the EBSD mapping analysis using a higher resolution step size of $1 \mu \mathrm{m}$. Figure 16 shows the overlaid images of

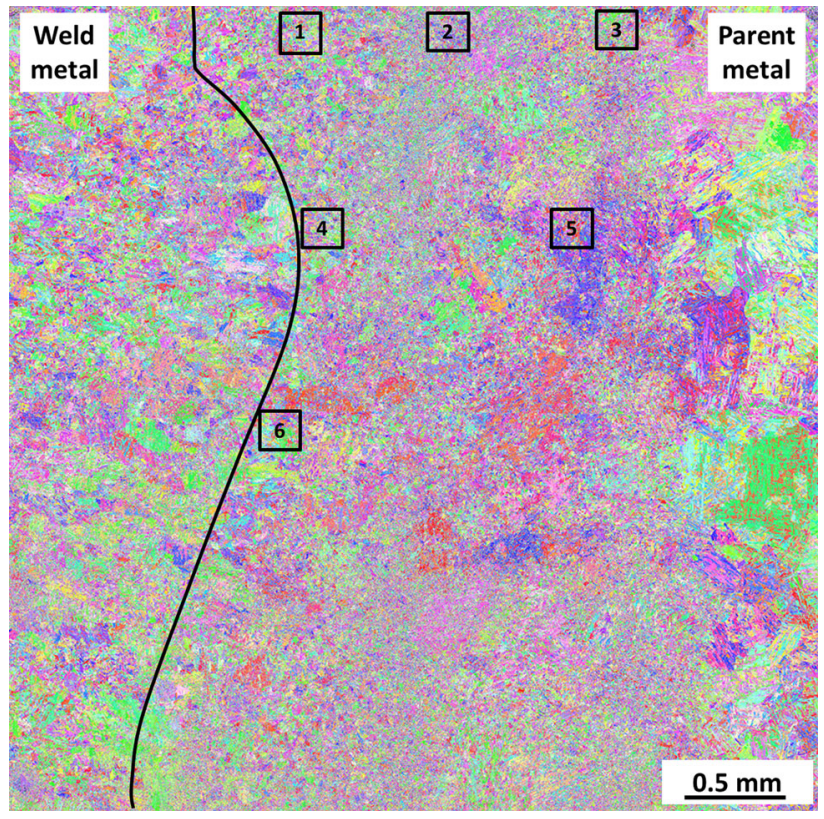

Fig. 15-Large-scale montage of the EBSD grain orientation maps providing an overview of the grain structure in the region, as indicated in Fig. 14 by the dashed box. The solid line and the black boxes indicate the fusion line and the regions where the subsequent EBSD analyses at a higher magnification, as shown in Fig. 16, were performed, respectively. the EBSD grain orientation and the gray-scale EBSD image quality maps that were collected from regions 1 through 6 and the schematic diagrams of the grain boundaries in the corresponding regions.

The grain structure in the HAZ was mainly composed of PAGs with a size of approximately $50 \mu \mathrm{m}$ (Figure 16(a), region 1), and then, with increasing distance from the weld line, changed to a finer grain structure composed of PAGs with a size of less than 20 $\mu \mathrm{m}$ (Figure 16(b), region 2), and then further to a grain structure that was a combination of the PAGs with a size of less than $20 \mu \mathrm{m}$ and the larger PAGs with a size of over $60 \mu \mathrm{m}$ (Figure 16(c), region 3). The grain structure in region 4 was found to be composed of PAGs with a size of $\sim 50 \mu \mathrm{m}$ and PAGs with a size of less than $20 \mu \mathrm{m}$ (Figure 16(d)). The grain structure in region 5 was similar to region 3 , in which a duplex grain structure of PAGs of less than $20 \mu \mathrm{m}$ and larger PAGs with a size of larger than $60 \mu \mathrm{m}$ was observed (Figure 16(e)). The grain structure in region 6 (Figure 16(f)) was similar to region 1, in which the grain structure was predominantly composed of PAGs with a size of approximately $50 \mu \mathrm{m}$.

Ion-beam-induced secondary electron imaging was performed in the HAZ of the multipass SAW weld to characterize the distribution characteristics of secondary precipitate particles. Figure 17 shows the ion-beam-induced secondary electron micrographs that were collected from the regions 1 through 6 , as indicated in Figure 15.

The presence of secondary precipitate particles was not observed in regions 1 and 4, whereas in region 2, a small number of particles with a size of less than $100 \mathrm{~nm}$ were observed. In both regions 3 and 5, the presence of the secondary precipitate particles with a size of $\sim 200$ $\mathrm{nm}$ and smaller ones with a size of less than $100 \mathrm{~nm}$ were observed. The number density of the particles in region 3 was found to be higher than that in region 5. The secondary precipitate particles that were detected in region 6 were found to be less than $100 \mathrm{~nm}$ in size. Some stringers of particles have also been observed in region
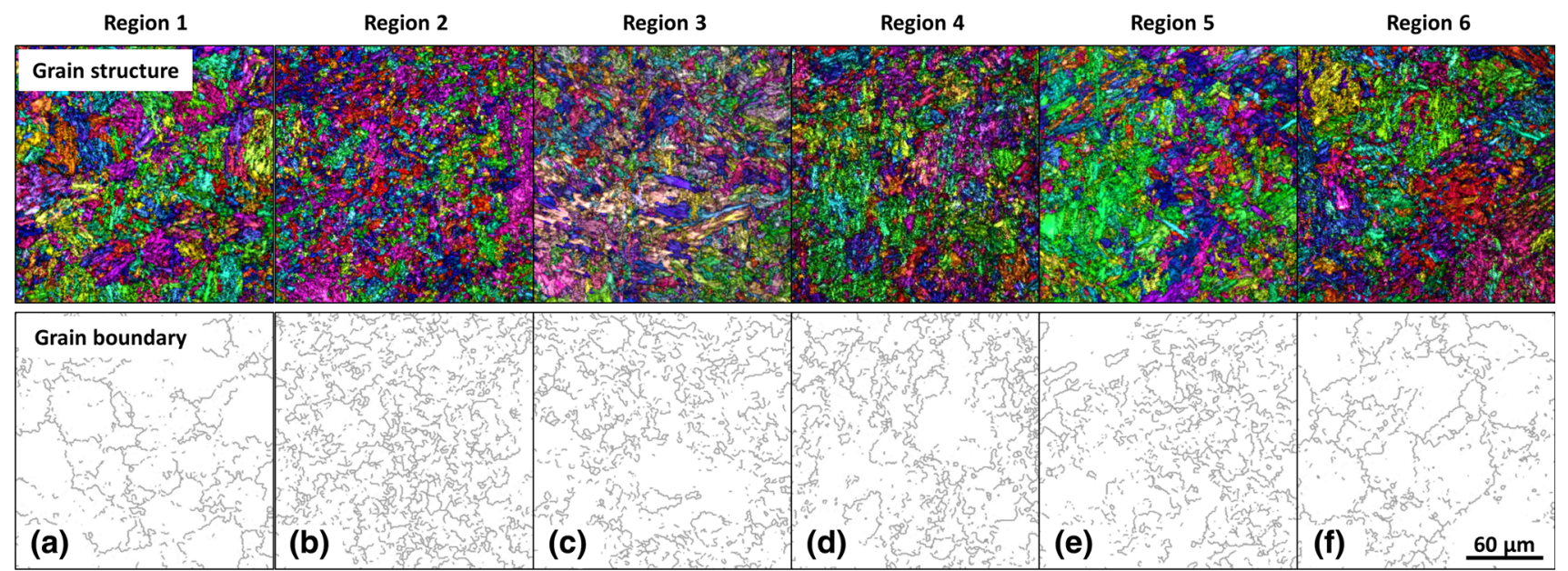

Fig. 16- Overlaid images of the colored EBSD grain orientation and the gray-scale EBSD image quality maps showing the grain structure in the regions, as labelled in Fig. 15 as regions $(a) 1,(b) 2,(c) 3,(d) 4,(e) 5$, and $(f) 6$. The EBSD grain boundary maps that exhibit the 20 through 50 deg boundary in regions 1 through 6 are also included for comparison. 
6, which suggests that these particles are distributed on lath and grain boundaries, as has been observed in previous studies. ${ }^{[3]}$ These particles, although with small sizes of less than $100 \mathrm{~nm}$, are likely to be the $\mathrm{M}_{23} \mathrm{C}_{6}$ carbides consistent with those observed in the HAZ-simulated material that was exposed to weld thermal cycles with peak temperatures of $1523 \mathrm{~K}+1103 \mathrm{~K}\left(1250{ }^{\circ} \mathrm{C}+\right.$ $\left.830{ }^{\circ} \mathrm{C}\right)$ (Figure 11).

\section{DISCUSSION}

\section{A. Comparisons Between the Double-Pass and the Multipass Welds}

The hardness in the HAZ of the double-pass weld sample (Figure 12) was found to possess a similar distribution to that of the HAZ in the multipass weld sample (Figure 14). Similarities in grain structure and distribution characteristics of secondary precipitates were also observed between the two weld samples (Figures 13 and 15). Considering that these two weld samples share an identical parent metal, it is expected that-provided the experiments are well controlled and well understood - the thermal history in the HAZ of the multipass weld should be equivalent to a two-pass bead-on-plate condition.

\section{B. Classification of the Microstructure in the Overlapped $H A Z$}

Figure 18 presents a schematic diagram illustrating the overlap of the CT-, the PT-, and the OT-HAZ regions for an overlapped two-bead scenario, building on the previous development of a classification scheme for the HAZ for $9 \mathrm{Cr}$ steels. ${ }^{[3]}$ This figure shows all of the possible HAZ thermal cycle combinations, although some of these classifications are redundant since a specific peak temperature [such as $1523 \mathrm{~K}\left(1250^{\circ} \mathrm{C}\right)$ ] can effectively reset the microstructure regardless of the previous peak temperatures. Furthermore, peak temperatures, which are less than the $A c_{1}$, do not appear to markedly affect the observed microstructure.

\section{The CT-CT, PT-CT, and OT-CT regions}

It has been observed that when a peak temperature is experienced greater than the $A c_{3}$ temperature [e.g., $1523 \mathrm{~K}\left(1250{ }^{\circ} \mathrm{C}\right)$ in this set of experiments] during the second thermal cycle, the grain structure in the dilatometry simulated samples is predominantly composed of PAGs with a size of approximately $50 \mu \mathrm{m}$ (Figures 8(a) and (d)). A complete dissolution of the pre-existing secondary precipitate particles from the original matrix of the parent metal was also observed in these samples (Figures 9(a) and (d)). Similar microstructural properties were observed in the weld HAZs in the regions close to the fusion line of the second bead in the two-pass bead-on-plate weld (Figure 13) and in region 1 of the multipass weld (Figures 16(a) and 17(a)).

In a previous study, in which the effects of weld thermal cycles on the microstructure of the HAZ were studied in detail, ${ }^{[3]}$ it has been observed that the typical
PAG size in the HAZ-simulated material that was exposed to single weld thermal cycle with a peak temperature above the $A c_{3}$ temperature $[e . g ., 1523 \mathrm{~K}$ $\left(1250{ }^{\circ} \mathrm{C}\right)$ ] was approximately $50 \mu \mathrm{m}$, which is similar to the observations from the double-pass HAZ-simulated material after a second thermal cycle with a similar peak temperature [i.e., $1523 \mathrm{~K}\left(1250{ }^{\circ} \mathrm{C}\right)$ ]. Another microstructural similarity between these two samples is that the pre-existing precipitate particles in the parent metal were completely dissolved after simulation of the weld thermal cycles. ${ }^{[3]}$ A systematic study of the influence of peak temperature on the dissolution behavior of pre-existing precipitates, such as the $\mathrm{M}_{23} \mathrm{C}_{6}$ carbides and the MX carbonitrides, has indicated that the pre-existing $\mathrm{M}_{23} \mathrm{C}_{6}$ carbides and $\mathrm{MX}$ carbonitrides are not completely dissolved until the peak temperatures of weld thermal cycles reached $1273 \mathrm{~K}$ and $1523 \mathrm{~K}$ $\left(1000{ }^{\circ} \mathrm{C}\right.$ and $1250{ }^{\circ} \mathrm{C}$ ), respectively (Figure 11 in Reference 3$)$.

The dissolution temperatures of the $\mathrm{M}_{23} \mathrm{C}_{6}$ carbides and the MX carbonitrides were also calculated for the thermodynamic equilibrium state. Figure 19 shows a graph showing the variation of phase fractions against the variation of temperature at the thermodynamic equilibrium state calculated using thermodynamic modeling software.

At the thermodynamic equilibrium state, the $\mathrm{M}_{23} \mathrm{C}_{6}$ carbides start dissolving at approximately $1073 \mathrm{~K}$ $\left(800{ }^{\circ} \mathrm{C}\right)$ and are completely dissolved at approximately $1183 \mathrm{~K}\left(910^{\circ} \mathrm{C}\right)$. The $\mathrm{MX}$ carbonitrides are stable to higher temperatures, start dissolving at approximately $1223 \mathrm{~K}\left(950^{\circ} \mathrm{C}\right)$, and are completely dissolved at approximately $1473 \mathrm{~K}\left(1200^{\circ} \mathrm{C}\right)$. Compared to the experimental measurements that were obtained from the HAZ-simulated materials, ${ }^{[3]}$ the experimentally measured temperatures at which these precipitates start and finish dissolving are higher than the values predicted for the thermodynamic equilibrium state. This is because the weld thermal cycles possess extremely high heating and cooling rates (i.e., 60 and $40 \mathrm{~K} / \mathrm{s}$, respectively), which do not allow thermodynamic equilibrium to be attained.

In addition, the presence of nanoscale $\mathrm{M}_{3} \mathrm{C}$ precipitates as a result of auto-tempering has been observed after a single-pass weld thermal cycle simulation with a peak temperature of $1523 \mathrm{~K}\left(1250{ }^{\circ} \mathrm{C}\right) .{ }^{[3]}$ Similar precipitation behavior is also likely to occur in the HAZ-simulated materials and the regions in the HAZs of double-pass and multipass welds, which were exposed to a second thermal cycle with a similar peak temperature. However, it has been reported that these $\mathrm{M}_{3} \mathrm{C}$ precipitates are not thermally stable and, thus, further transform to the more stable $\mathrm{M}_{23} \mathrm{C}_{6}$ carbides during subsequent heat treatment. ${ }^{[18]}$

A hardness of higher than $450 \mathrm{HV}_{0.2}$ was measured in the regions from the weld $\mathrm{HAZs}$ that are close to the weld line of the second weld bead of the double-pass weld and region 1 in multipass weld regions. Comparing with the single-pass HAZ-simulated material that was exposed to weld thermal cycles with similar peak temperatures (Figure 7 in Reference 3), the hardnesses in these regions and the double-pass simulated samples 

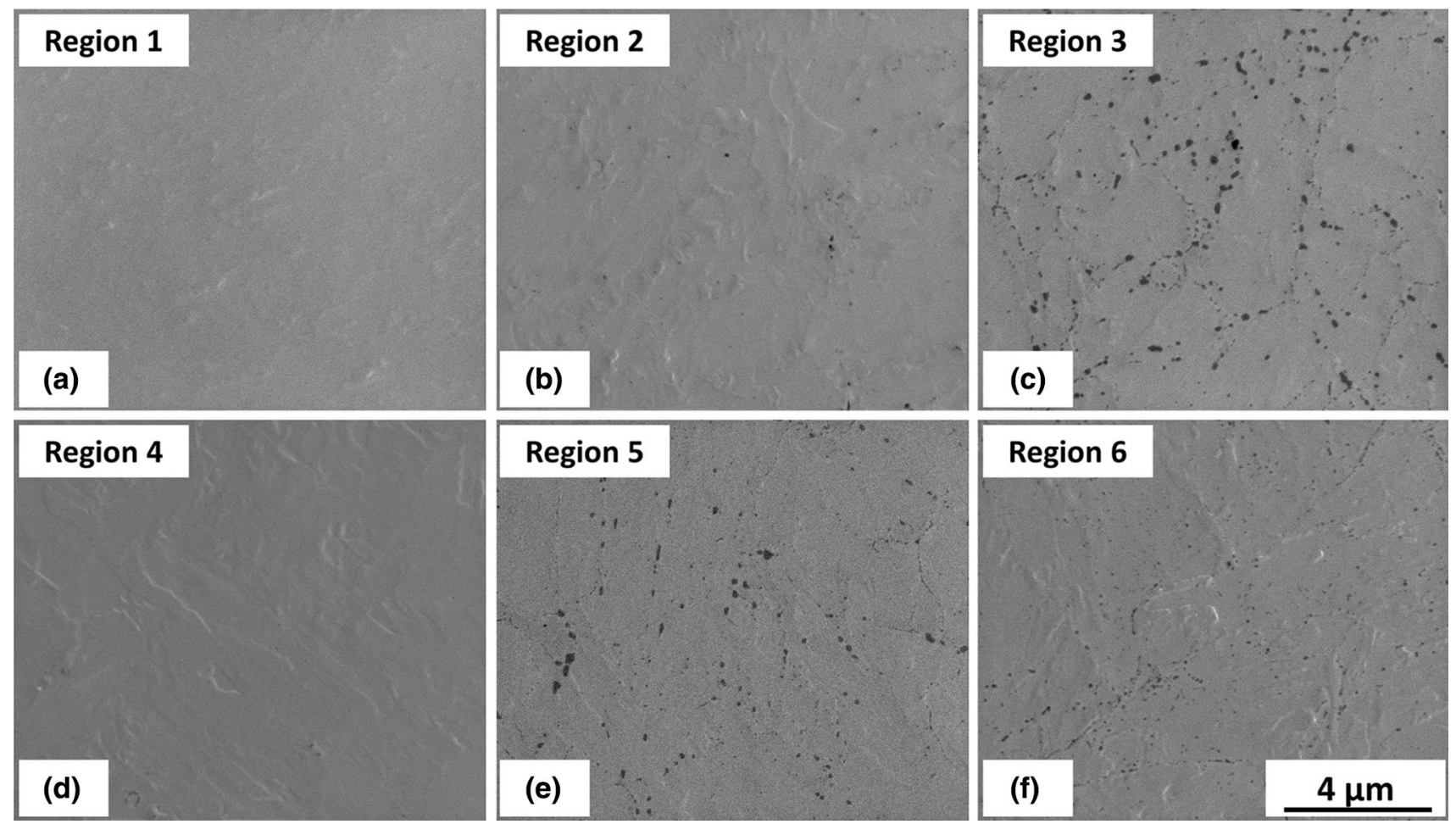

Fig. 17-Ion-beam-induced secondary electron micrographs $(a)$ through $(f)$ showing the secondary precipitate particles in the HAZ. The regions where the micrographs were collected are indicated in Fig. 15 as regions (a) 1, (b) 2, (c) 3, (d) 4, (e) 5 and (f) 6.

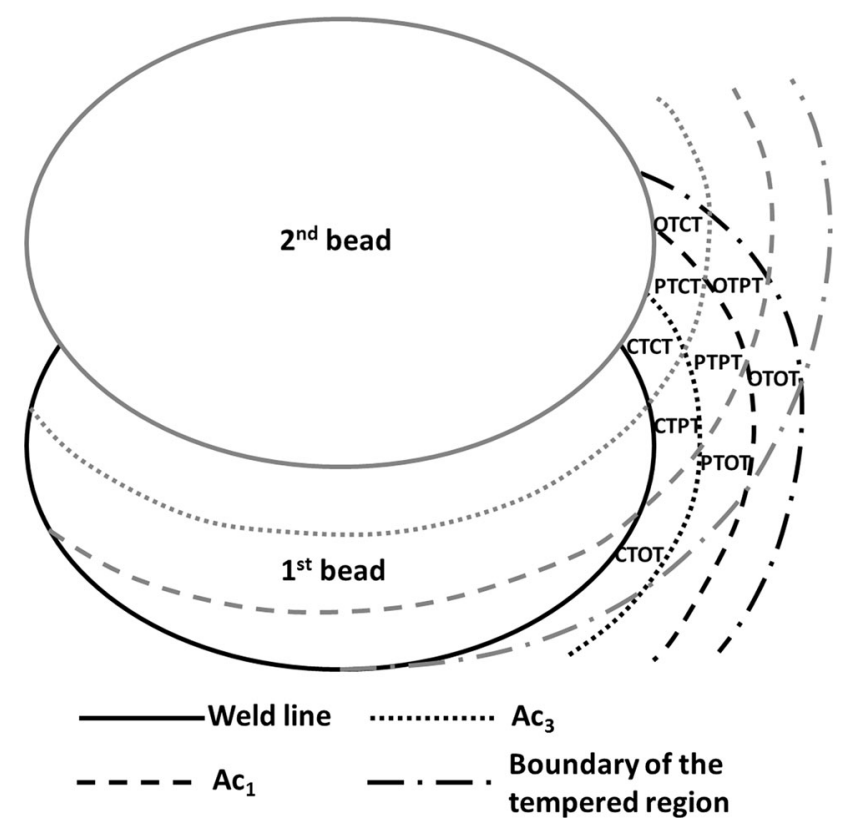

Fig. 18-Schematic diagram showing the classification of the microstructure in the HAZ of a double-pass Grade 92 steel weld based on the ranges of thermal cycle peak temperatures.

that were exposed to a second thermal cycle with a peak temperature of $1523 \mathrm{~K}\left(1250{ }^{\circ} \mathrm{C}\right)$ are at a similar level. This is mainly attributed to a grain structure that is predominantly composed of freshly formed, untempered martensite after complete reaustenitization of the original parent metal microstructure (e.g., Figures $8(\mathrm{a})$ and 16(a)).

To summarize, the key microstructural properties in the regions that are close to the weld line of the second weld bead of the double-pass weld and the regions 1, 4, and 6 (Figure 15) in the multipass weld include a completely reaustenitized matrix and a complete dissolution of secondary precipitate particles. Similarities in microstructure have been observed between these regions and the HAZ-simulated materials that were exposed to a second thermal cycle with a peak temperature above the $A c_{3}$ temperature. These regions are, therefore, labeled as the CT-CT, PT-CT, and OT-CT regions in Figure 18.

\section{The CT-PT, PT-PT, and OT-PT regions}

The experimental observations from the HAZ-simulated materials have indicated that upon an intercritical peak temperature of between the $A c_{1}$ and the $A c_{3}$ temperatures during the second thermal cycle, the pre-existing grain structure after the first weld thermal cycle was further refined. For the simulated samples that were exposed to a peak temperature of close to the $A c_{3}$ temperature (e.g., $\left.1273 \mathrm{~K}\left(1000{ }^{\circ} \mathrm{C}\right) \approx A c_{3}-57 \mathrm{~K}\right)$ during either the first or the second thermal cycle, a refined grain structure, with a grain size of less than 20 $\mu \mathrm{m}$, was observed (e.g., Figure 8(e)). When a region experiences a peak temperature that is near the $A c_{1}$ temperature (e.g., $\left.1173 \mathrm{~K}\left(900{ }^{\circ} \mathrm{C}\right) \approx A c_{1}+23 \mathrm{~K}\right)$ during both the first and the second thermal cycles, the original matrix of the parent metal is not completely reaustenitized and, hence, exhibits a duplex 
microstructure showing fine PAGs that are distributed on the pre-existing PAGBs in the parent metal (e.g., Figure 8(f)). Similar grain structures were observed in the weld HAZs, such as in regions 2 and 4 in the multipass weld (e.g., Figures 16(b) and (d)). These regions are consistent with the classified regions labeled as the CT-PT, PT-PT, and OT-PT regions in Figure 18.

Microstructural observations from the HAZ-simulated materials that were exposed to the simulations of single-pass weld thermal cycles, as presented in a previous study, ${ }^{[3]}$ have clearly indicated the process of the reaustenization of the original matrix during welding. It has been observed that reaustenization preferentially starts from the pre-existing PAGBs, giving rise to fine martensitic laths in small PAGs with sizes of less than $10 \mu \mathrm{m}$ (Figure 8(d) in Reference 3). As the peak temperature of the weld thermal cycle increases to slightly above the $A c_{1}$ temperature (e.g., $1173 \mathrm{~K}$ $\left(900{ }^{\circ} \mathrm{C}\right)$, as chosen in Reference 3$)$, the resulting microstructure after welding is composed of refined martensitic structure in the reaustenitized regions and coarser martensitic laths that remain in the regions that were not reaustenitized (Figure 8(c) in Reference 3). As the peak temperature of weld thermal cycles further increases to close to the $A c_{3}$ temperature $(e . g ., 1273 \mathrm{~K}$ $\left(1000{ }^{\circ} \mathrm{C}\right)$, as chosen in Reference 3$)$, the original matrix in the parent metal was fully reaustenitized, giving rise to a refined martensitic grain structure with PAG sizes of less than $20 \mu \mathrm{m}$ (Figure 8(b) in Reference 3).

Comparing with the observations from the double-pass HAZ-simulated materials, a similar trend in microstructure against the variation of peak temperature was observed. As the peak temperature of the second thermal cycle is close to the $A c_{3}$ temperature, the pre-existing microstructure after the first thermal cycle, regardless of the peak temperature, is fully reaustenitized to a refined martensitic microstructure (e.g., Figure $8(\mathrm{e}))$. However, if the peak temperature of the second thermal cycle is close to the $A c_{1}$ temperature, the pre-existing microstructure after the first thermal cycle is partially reaustenitized. For instance, if the original matrix of the parent metal has been previously fully reaustenitized to a grain structure with typical PAG sizes at approximately $50 \mu \mathrm{m}$ after the first thermal cycle with a peak temperature of above the $A c_{3}$ temperature [e.g., $\left.1523 \mathrm{~K}\left(1250{ }^{\circ} \mathrm{C}\right)\right]$, the resulting microstructure after the second thermal cycle is a combination of the pre-existing, relatively coarser martensites with PAG sizes at approximately $50 \mu \mathrm{m}$ and refined martensites that are formed during the second thermal cycle, as observed in the " $1523 \mathrm{~K}+1173 \mathrm{~K}\left(1250{ }^{\circ} \mathrm{C}+\right.$ $900{ }^{\circ} \mathrm{C}$ )" HAZ-simulated sample (Figure 8(b)).

The hardness of the dilatometry simulated samples that were exposed to a peak temperature of between the $A c_{1}$ and the $A c_{3}$ temperatures during the second thermal cycle was found to vary (Figure 7). When the peak temperature of the second thermal cycle is close to the $A c_{3}$ temperature, the hardness of the simulated sample was found to be higher than $460 \mathrm{HV}_{0.2}$, which can be attributed to a matrix that is predominantly composed of the freshly formed untempered martensite after weld thermal cycle simulations. When the peak temperatures of both the first and the second weld thermal cycles are close to the $A c_{1}$ temperature, a lower hardness with a higher standard deviation between measurements was observed, which is attributable to a partially reaustenitized matrix after the weld thermal cycle simulations.

The presence of undissolved secondary precipitate particles from the parent metal was observed in the dilatometry simulated samples that were exposed to intercritical peak temperatures during both the first and the second thermal cycles (Figures 9(e) and (f)). Consistent with the previous work, ${ }^{[3]}$ the pre-existing secondary precipitate particles in the parent metal are only partially dissolved upon experiencing a peak temperature of between the $A c_{1}$ and the $A c_{3}$ temperatures [e.g., $1273 \mathrm{~K}\left(1000{ }^{\circ} \mathrm{C}\right)$, as chosen in Reference 3], which is consistent with the observations from both the dilatometry samples that were exposed to the simulations of double-pass weld thermal cycles and the HAZs of the double-pass and the multipass welds. It has been observed that when a region experiences a peak temperature of close to the $A c_{3}$ temperature, the remaining precipitates are predominantly MX, whereas for temperatures closer to the $A c_{1}$ temperature, the remaining precipitates are both $\mathrm{M}_{23} \mathrm{C}_{6}$ and $\mathrm{MX}$. This is consistent with previous observations from the single-pass HAZ-simulated materials, ${ }^{[3]}$ which show that the thermally sensitive $\mathrm{M}_{23} \mathrm{C}_{6}$ carbides started dissolving prior to the dissolution of the MX carbonitrides. Therefore, the fine precipitate particles that were observed in the " $1273 \mathrm{~K}+1273 \mathrm{~K}\left(1000{ }^{\circ} \mathrm{C}+1000{ }^{\circ} \mathrm{C}\right)$ " HAZ-simulated material are likely to be undissolved MX carbonitride particles that remained after simulation of weld thermal cycles (Figure 9(e)). The larger precipitate particles that were observed in the "1173 K + $1173 \mathrm{~K}$ $\left(900{ }^{\circ} \mathrm{C}+900{ }^{\circ} \mathrm{C}\right)$ " $\mathrm{HAZ}$-simulated material, however, are the undissolved $\mathrm{M}_{23} \mathrm{C}_{6}$ carbide particles (Figure 9(f)).

Combining the observations of grain structure in the weld HAZs, the remaining precipitates in the regions showing a refined grain structure (e.g., region 2 in Figure 17) are likely to be of the MX type, whereas the remaining particles in the partially reaustenitized regions (e.g., regions 3 and 5 in Figure 17) consist of both $\mathrm{M}_{23} \mathrm{C}_{6}$ - and $\mathrm{MX}$-type carbonitrides.

\section{The CT-OT, PT-OT, and OT-OT regions}

It has been observed that the pre-existing grain structure after the first thermal cycle was not significantly changed during the second thermal cycle with a peak temperature of lower than the $A c_{1}$ temperature [e.g., $\left.1103 \mathrm{~K}\left(830^{\circ} \mathrm{C}\right)\right]$. For instance, in the " $1523 \mathrm{~K}+$ $1103 \mathrm{~K}\left(1250{ }^{\circ} \mathrm{C}+830^{\circ} \mathrm{C}\right)$ " HAZ-simulated sample, the resulting grain structure after the simulation of double-pass weld thermal cycles is similar to the grain structure that is formed after single thermal cycle with a peak temperature of $1523 \mathrm{~K}\left(1250{ }^{\circ} \mathrm{C}\right)$, as presented in the previous study. ${ }^{[3]}$ However, the hardness of these samples that were exposed to the simulations of double-pass weld thermal cycles is lower than the samples that were exposed to single-pass simulations with a similar peak temperature as the first cycle. For example, the hardness of the $1523 \mathrm{~K}+1103 \mathrm{~K}\left(1250{ }^{\circ} \mathrm{C}+\right.$ 


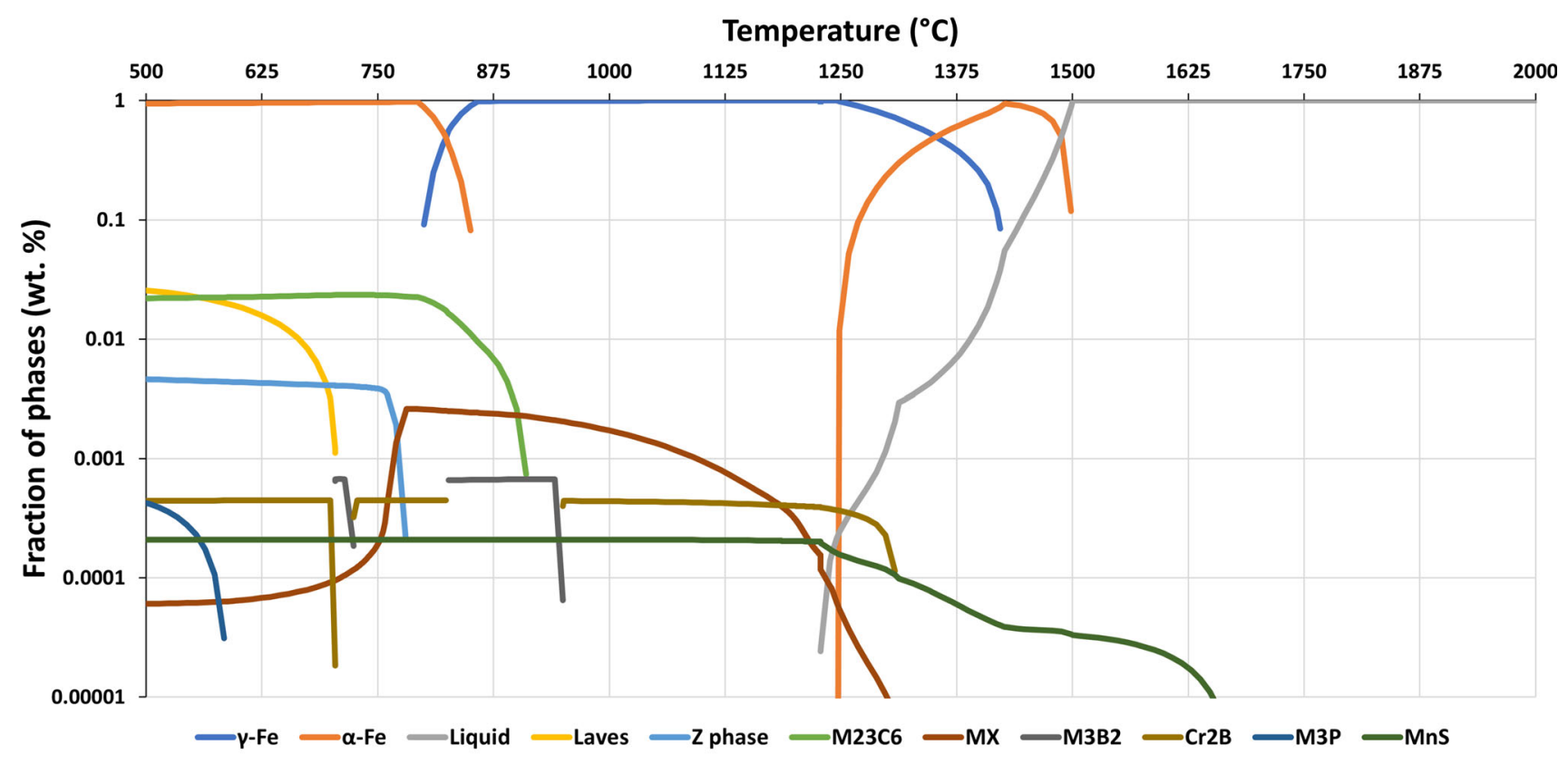

Fig. 19-Graph showing the variation of phase fractions against temperature for the thermodynamic equilibrium state, as calculated by Thermo-calc software version $2016 \mathrm{~b}$ using a TCFE 7 database using the chemical composition given in Table I.

$830{ }^{\circ} \mathrm{C}$ ) HAZ-simulated sample (i.e., $376 \mathrm{HV}_{0.2}$ ) is lower than the hardness after a single-pass thermal cycle with a peak temperature of $1523 \mathrm{~K} \quad\left(1250^{\circ} \mathrm{C}\right)$ (i.e., 472 $\left.\mathrm{HV}_{0.2}{ }^{[3]}\right)$.

In the previous study, it has been observed that after the exposure to a weld thermal cycle with a peak temperature of lower than the $A c_{1}$ temperature [e.g., $1103 \mathrm{~K}\left(830^{\circ} \mathrm{C}\right)$ ], the pre-existing microstructure was not significantly changed ${ }^{[3]}$ since the peak temperature was not high enough to induce reaustenitization. The pre-existing precipitates, particularly the thermally sensitive $\mathrm{M}_{23} \mathrm{C}_{6}$ carbides, are slightly coarsened after the weld thermal cycles, accompanied by an obvious drop in hardness due to the tempering effect from the weld thermal cycles with such low peak temperatures. ${ }^{[3]}$ These observations from single-pass HAZ-simulated materials are similar to the observations from the double-pass HAZ-simulated materials and the HAZs in the double-pass and multipass welds obtained in this study. Regions showing similar microstructural properties and hardness values were also observed in the weld HAZs, such as in region 6 from the multipass weld. These microstructural features correspond to regions such as the CT-OT, PT-OT, and OT-OT regions in Figure 18.

Stringers of fine precipitates with a size of less than $100 \mathrm{~nm}$ were observed by ion-beam-induced secondary electron imaging in both the simulated samples that were exposed to a peak temperature of less than $A c_{1}$ temperature during the second thermal cycle (Figure 9(c)) and the corresponding regions with similar thermal histories in the weld HAZs (Figure 17(f)). These fine precipitates were identified as the $\mathrm{M}_{23} \mathrm{C}_{6}$ carbides by TEM analysis (Figure 11) but are much finer than the pre-existing $\mathrm{M}_{23} \mathrm{C}_{6}$ particles in the parent metal.

Owing to significantly different distribution characteristics and particle sizes, these fine $\mathrm{M}_{23} \mathrm{C}_{6}$ carbides are not the pre-existing $\mathrm{M}_{23} \mathrm{C}_{6}$ precipitates that originate from the parent metal but are newly formed precipitates during simulation of the weld thermal cycles. The critical peak temperature below which these small particles start to be observed after the simulation of double-pass weld thermal cycles is approximately $1173 \mathrm{~K}\left(900{ }^{\circ} \mathrm{C}\right)$ (Figure $10(\mathrm{~b})$ ), above which the presence of these small particles was not observed due to a complete dissolution of these particles upon the exposure to higher peak temperatures (Figure 19). The smaller sizes of these precipitates can be attributed to the high heating and cooling rates and short holding time periods at peak temperature of weld thermal cycles, which provides much shorter time periods for the growth of these precipitates.

The $\mathrm{M}_{23} \mathrm{C}_{6}$ carbide particles were found to be formed on the newly formed PAGBs and along substructure boundaries since these have been reported as the preferred locations for precipitation of these particles. ${ }^{[1]}$ However, the presence of the stringers of small $\mathrm{M}_{23} \mathrm{C}_{6}$ carbides that are not distributed on a distinct PAG or substructure boundary was also observed (Figure 10). Similar observations have been reported ${ }^{[15]}$ on a simulated HAZ material that is exposed to a single-pass weld thermal cycle simulation with a peak temperature of close to the $A c_{3}$ temperature followed by a standard postweld heat treatment process. The observation of the 
Table IV. A Summary of Microstructural Properties and Hardness in the Different Regions that Have Various Thermal Histories in the Overlapped HAZ Region of a Double-Pass Grade 92 Weld

\begin{tabular}{|c|c|c|c|}
\hline Regions & Hardness & Grain Structure & Secondary Precipitates \\
\hline $\begin{array}{l}\text { СТCT, РTCT, } \\
\text { OTCT }\end{array}$ & over $460 \mathrm{HV}_{0.2}$ & $\begin{array}{l}\text { completely reaustenitized matrix with } \mathrm{PAG} \\
\text { size at } 50 \mu \mathrm{m}\end{array}$ & complete dissolution of the pre-existing particles \\
\hline $\begin{array}{l}\text { CTPT, PTPT, } \\
\text { OTPT }\end{array}$ & $\begin{array}{l}250 \text { to over } \\
460 \mathrm{HV}_{0.2}\end{array}$ & $\begin{array}{l}\text { second-cycle peak temperatures close to } A c_{3} \text { : } \\
\text { completely reaustenitized matrix with PAG } \\
\text { size at less than } 20 \mu \mathrm{m} \text {; } \\
\text { second-cycle peak temperatures close to } A c_{1} \text { : } \\
\text { partially reaustenitized matrix }\end{array}$ & $\begin{array}{l}\text { CTPT: complete dissolution of } \\
\text { the pre-existing particles; } \\
\text { PTPT, OTPT: incomplete dissolution of the } \\
\text { pre-existing particles from the parent metal }\end{array}$ \\
\hline $\begin{array}{l}\text { CTOT, PTOT, } \\
\text { OTOT }\end{array}$ & $\begin{array}{l}\text { less than } 220 \\
\text { to } 400 \mathrm{HV}_{0.2}\end{array}$ & $\begin{array}{l}\text { CTOT: completely reaustenitized with PAG } \\
\text { size at } 50 \mu \mathrm{m} \text {; } \\
\text { PTPT: partially reaustenitized matrix; } \\
\text { OTOT: similar grain structure to the } \\
\text { parent metal }\end{array}$ & $\begin{array}{l}\text { coarsening of the remained precipitate particles; } \\
\text { formation of small } \mathrm{M}_{23} \mathrm{C}_{6} \text { carbides in } \\
\text { the reaustenitized regions }\end{array}$ \\
\hline
\end{tabular}

apparent random orientation of $\mathrm{M}_{23} \mathrm{C}_{6}$ particles (i.e., not located on an apparent boundary) was attributed to the local segregation of the alloy elements, such as $\mathrm{Cr}$ and $\mathrm{C}$, after the dissolution of the pre-existing $\mathrm{M}_{23} \mathrm{C}_{6}$ during the first weld thermal cycle, which leads to the formation of fine $\mathrm{M}_{23} \mathrm{C}_{6}$ carbides during the second cycle. This has been considered as an important metallurgical contribution linked to HAZ failures in martensitic steels. ${ }^{[12]}$

Table IV summarizes the microstructural characteristics in the regions in the HAZ that were exposed to various weld thermal histories. The regions that were exposed to a peak temperature of above the $A c_{3}$ temperature in the later thermal cycle (i.e., the CT-CT, PT-CT, and OT-CT regions) can be differentiated from the other regions by a grain structure that is composed of the PAGs with a size of approximately $50 \mu \mathrm{m}$. This is because the initial microstructures after the first thermal cycles were reset during the later cycle, giving rise to a relatively coarser PAG structure that was typical after weld thermal cycles with peak temperatures above the $A c_{3}$ temperature. Notably, in the materials that were exposed to a PT-CT type of weld thermal cycle, a slightly higher fraction of the grains with smaller sizes of less than $20 \mu \mathrm{m}$ were observed. This is because the grain size after the exposure to a first thermal cycle with a peak temperature of between the $A c_{1}$ and the $A c_{3}$ temperatures is significantly smaller than the other samples (i.e., CT-CT or OT-CT), which does not allow a grain size at similar levels to be obtained after the second cycle. However, the presence of the relatively larger PAGs with sizes of approximately $50 \mu \mathrm{m}$ is indicative of the regions in which the microstructure was reset by a final thermal cycle with a peak temperature of above the $A c_{3}$ temperature. The regions that were exposed to an intercritical peak temperature of between the $A c_{1}$ and the $A c_{3}$ temperatures (i.e., the CT-PT, PT-PT, and OT-PT regions) are identified with a refined grain structure that is composed of the small PAGs with a size of less than $20 \mu \mathrm{m}$, as the peak temperatures were higher, close to the $A c_{3}$ temperature. As the peak temperatures of weld thermal cycles were close to the $A c_{1}$ temperature, the presence of the coarser lathlike grains that were originated from the parent metal was observed in these regions due to partial reaustenitization of the original parent metal microstructure. The regions that were exposed to a peak temperature of below the $A c_{1}$ temperature in the later thermal cycle (i.e., the CT-OT, PT-OT, and OT-OT regions) are identified with a local decrease of hardness, and the resulting grain structures in these regions are determined during the previous thermal cycle. Figure 20 proposes an exemplary classification of the microstructure in the HAZ of the multipass weld sample based on the experimental observations from this study.

\section{Microstructural influence on creep properties}

It has been established that HAZ failures in 9 wt pct $\mathrm{Cr}$ steel weldments occur in a region that is not coincident with the weld line and is close to the boundary between the HAZ and the parent metal. ${ }^{[16]}$ Regardless of the previous classification for martensitic steel HAZ regions, it is clear that the region most susceptible to long-term creep failure is one that possesses both a less-than-ideal grain and precipitate structure. Based on the results reported here, it is clearly the case that the PT region, either as a result of a single thermal cycle or the PT region imposed on a pre-existing region in the $\mathrm{HAZ}$, results in an inferior microstructure for long-term creep resistance. In general, it can be said that this region relates to exposures of the material to a peak thermal temperature between the $A c_{1}$ and the $A c_{3}$ temperatures during welding. The grain structure in a PT, OT-PT, PT-PT, or CT-PT region can be varied from a completely reaustenitized refined grain structure upon peak temperatures of close to the $A c_{3}$ temperature to a partially reaustenitized grain structure upon peak temperatures of close to the $A c_{1}$ temperature, which is consistent with the observations from the existing literature. ${ }^{[15,25]}$ The partially reaustenitized matrix, which exhibits significant microstructural heterogeneities, has been linked to the presence of HAZ failures in a recent article. ${ }^{[26]}$ Further work is under way to link the observations provided here to actual longterm creep test HAZ failures in an effort to better establish the influence of the welding thermal cycle on 

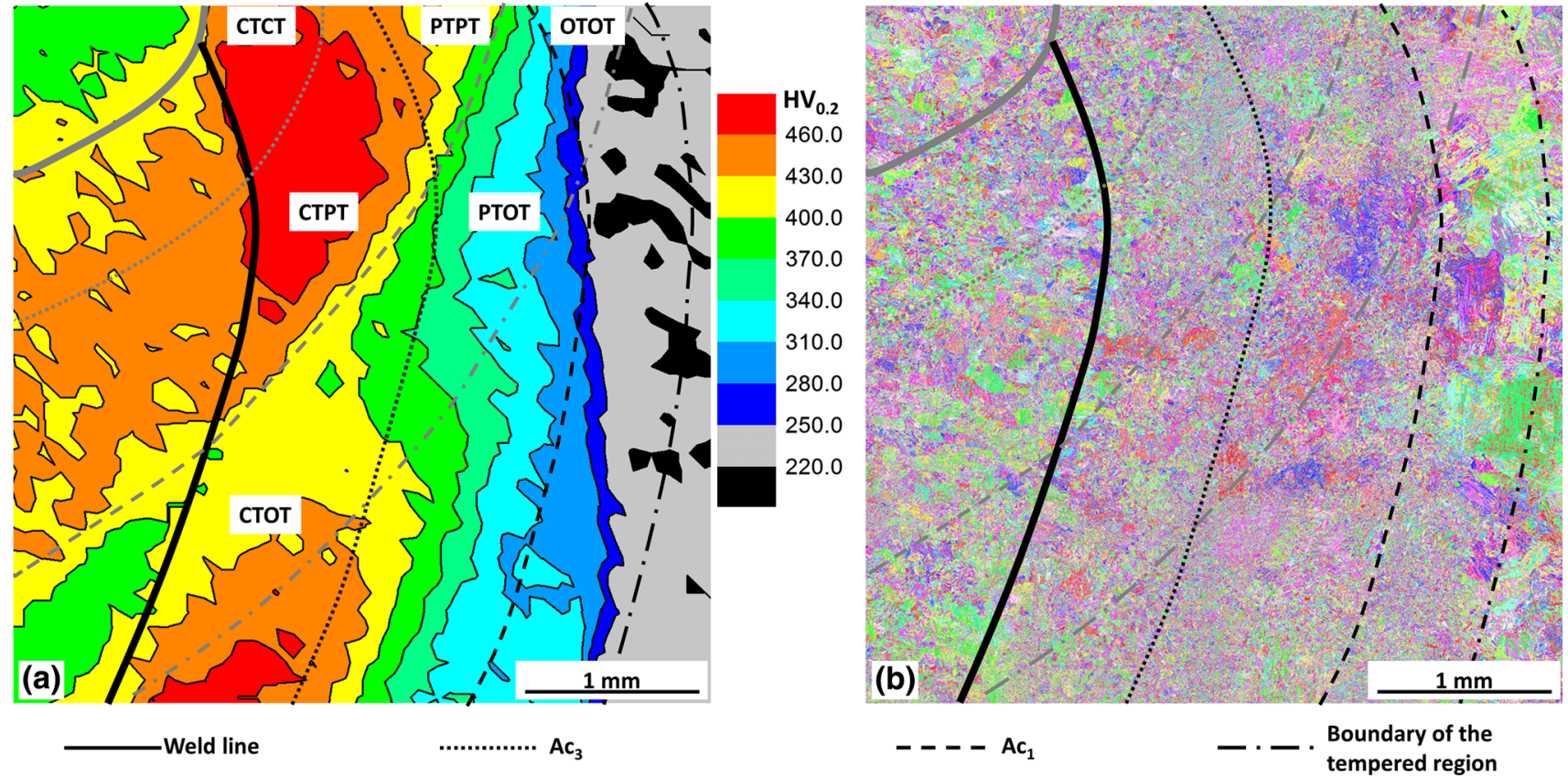

Fig. 20 - Classification of the microstructural variation in the overlapping HAZ region of a multipass weld in a parent metal of Grade 92 steel based on the variations in $(a)$ hardness and $(b)$ grain structure. The locations of the CTOT, PTOT, and OTOT regions were determined from the hardness of the different regions, as shown in (a). The locations of the CTCT, PTPT, and CTPT regions were determined from the variation in grain structure, as shown in (b)

the evolution of damage in the Grade $92 \mathrm{HAZ}$ in full scale components.

\section{CONCLUSIONS}

A detailed experimental assessment has been carried out to investigate the influence of multiple thermal cycles on regions within the HAZ of a high Cr steel weld. The microstructural distribution in the HAZ of multipass welds in Grade 92 steel, which have received multiple thermal cycles, can be classified as follows, based on the local thermal histories to which the regions within the HAZ were exposed during the welding process:

1. The CT-CT, PT-CT, and OT-CT regions, in which the peak temperature of the latter thermal cycle is above the $A c_{3}$ temperature, leading to a PAG size of approximately $50 \mu \mathrm{m}$ accompanied by a complete dissolution of secondary precipitate particles. In general, these regions may be simply classified as a "CT" region, because the microstructure is dominated by the CT thermal cycle.

2. The CT-PT, PT-PT, and OT-PT regions, in which the peak temperature of the second thermal cycle is between the $A c_{1}$ and the $A c_{3}$ temperatures, leading to a refined grain structure composed of PAGs with a size $<20 \mu \mathrm{m}$ and the presence of undissolved precipitate particles

3. The CT-OT, PT-OT, and OT-OT regions, where the peak temperature of the later thermal cycle is below the $A c_{1}$ temperature, leading to a decrease in hardness and the coarsening of pre-existing $\mathrm{M}_{23} \mathrm{C}_{6}$ carbides.

\section{OPEN ACCESS}

This article is distributed under the terms of the Creative Commons Attribution 4.0 International License (http://creativecommons.org/licenses/by/4.0/), which permits unrestricted use, distribution, and reproduction in any medium, provided you give appropriate credit to the original author(s) and the source, provide a link to the Creative Commons license, and indicate if changes were made.

\section{REFERENCES}

1. P. Ennis and A. Czyrska-Filemonowicz: Sadhana, 2003, vol. 28, pp. 709-30.

2. G.M. Marcello Consonni: Weld. Cutting, 2013, vol. 11, pp. $169-73$.

3. X. Xu, G.D. West, J.A. Siefert, J.D. Parker, and R.C. Thomson: Metall. Mater. Trans. A, 2017, vol. 48, pp. 5396-414.

4. A. Yaghi, T. Hyde, A. Becker, and W. Sun: J. Strain Anal. Eng. Des., 2008, vol. 43, pp. 275-93.

5. S. Issler, A. Klenk, A. Shibli, and J. Williams: Int. Mater. Rev., 2004, vol. 49, pp. 299-324.

6. D. Deng and H. Murakawa: Comput. Mater. Sci., 2006, vol. 37, pp. 269-77.

7. J. Gianetto, J. Braid, J. Bowker, and W. Tyson: J. Offshore Mech. Arct., 1997, vol. 119, pp. 134-44. 
8. S. Mannan and K. Laha: Trans. Ind. Inst. Met., 1996, vol. 49, pp. 303-20.

9. K. Laha, K. Chandravathi, P. Parameswaran, K.B.S. Rao, and S. Mannan: Metall. Mater. Trans. A, 2007, vol. 38A, pp. 58-68.

10. K. Chandravathi, K. Laha, K. Bhanu Sankara Rao, and S. Mannan: Mater. Sci. Technol., 2001, vol. 17, pp. 559-65.

11. K. Shinozaki, D. Li, H. Kuroki, H. Harada, K. Ohishi, and T. Sato: Sci. Technol. Weld. Join., 2003, vol. 8, pp. 289-95.

12. Y. Liu, S. Tsukamoto, T. Shirane, and F. Abe: Metall. Mater. Trans. A, 2013, vol. 44A, pp. 4626-33.

13. D. Li, K. Shinozaki, H. Harada, and K. Ohishi: Metall. Mater. Trans. A, 2005, vol. 36A, pp. 107-15.

14. H. Schuller, L. Hagn, and A. Woitscheck: Maschinenschaden, 1974, vol. 47, pp. 1-13.

15. J. Francis, W. Mazur, and H. Bhadeshia: Mater. Sci. Technol., 2006, vol. 22, pp. 1387-95.

16. T. Sakthivel, M. Vasudevan, K. Laha, P. Parameswaran, K. Chandravathi, S.P. Selvi, V. Maduraimuthu, and M. Mathew: Mater. Sci. Eng. A, 2014, vol. 591, pp. 111-20.

17. R.C. Maclachlan, J.J. Sanchez-Hanton, and R.C. Thomson: $A d-$ vances in Materials Technology for Fossil Power Plants: Proc. 6th
Int. Conf., ASM International, Materials Park, OH, 2011, pp. 787-99.

18. J. Robson and H. Bhadeshia: Mater. Sci. Technol., 1997, vol. 13, pp. 631-39.

19. W.B. Jones, C. Hills, and D. Polonis: Metall. Trans. A, 1991, vol. $22 \mathrm{~A}$, pp. $1049-58$.

20. A. Inoue and T. Masumoto: Metall. Trans. A, 1980, vol. 11A, pp. 739-47.

21. K. Sawada, T. Hara, M. Tabuchi, K. Kimura, and K. Kubushiro: Mater. Charact., 2015, vol. 101, pp. 106-13.

22. H. Kitahara, R. Ueji, N. Tsuji, and Y. Minamino: Acta Mater., 2006, vol. 54, pp. 1279-88.

23. L. Ryde: Mater. Sci. Technol., 2006, vol. 22, pp. 1297-1306.

24. K. Kaneko, S. Matsumura, A. Sadakata, K. Fujita, W. Moon, S. Ozaki, N. Nishimura, and Y. Tomokiyo: Mater. Sci. Eng. A, 2004, vol. 374 , pp. 82-89.

25. M. Yaguchi, T. Matsumura, and K. Hoshino: Proc. ASME 2012 Pressure Vessels and Piping Conf., Volume 6: Materials and Fabrication, ASME, New York, NY, 2012, pp. 317-26.

26. J. Lee and K. Maruyama: Met. Mater. Int., 2015, vol. 21 (4), pp. 639-45. 